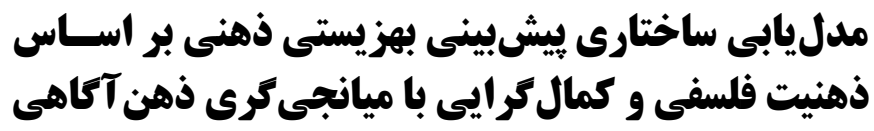

\title{
Structural Modeling of Subjective Well-Being Prediction Based on Philosophical Mentality and Perfectionism through Mediation of Mindfulness
}

\section{Hamed Mahzadeh ${ }^{1 *}$, Ali Pouladi Reyshahri², Molood Keikdosravani ${ }^{3}$, Seyed Musa Golestaneh ${ }^{4}$}

1. Ph. D. in General Psychology, Islamic Azad University of Bushehr Breach, Bushehr

2. Assistant Professor, Department of Psychology, Payame Noor University of Bushehr Breach, Bushehr

3. Assistant Professor, Department of Psychology, Islamic Azad university of Bushehr Breach, Bushehr

4. Assistant Professor, Department of Psychology of Education, Khalij Fars University of Bushehr Breach, Bushehr

\begin{abstract}
Health is a dynamic state in which individuals consistently adapt themselves to the internal and external changes. Different sciences and disciplines have addressed health issues, which among them, the community health disciplines have a special look at the subject. The purpose of this study was to investigate and develop a structural model for prediction of subjective well-being based on philosophical and perfectionism mentality through mediation of mindfulness in Tehran male employees. The present research was a correlation research and the target population of this study included all male employees of four state departments of Tehran in 2018. In this study, multi-stage cluster random sampling method was used. The sample size was 300 people according to the number of variables in the research. In this research the philosophical mentality, perfectionism, mindfulness, and subjective well-being questionnaires were used. Analyzing of data was performed using path analysis and structural modeling. The structural model of prediction of subjective well-being prediction based on philosophical mentality and perfectionism with the mediation of mindfulness in male employees was satisfactorily matched with research data $(p<0.05)$. Therefore, it can be concluded that the subjective well-being in the men employees of Tehran state departments is explained by the philosophical mindedness and perfectionism through mediation of mindfulness.
\end{abstract}

Keywords:

Subjective well-being, philosophical mentality, perfectionism, mindfulness, structural modeling

\author{
حامد ماهزاده '"، يولادى ريشهرى

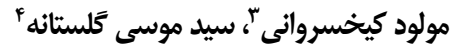

سلامت حالتى يوياست كه بر اساس آن افراد بلطور مداوم خود را با تغييرات

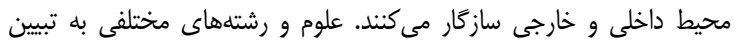

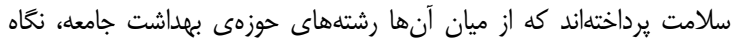

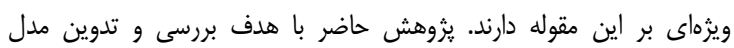

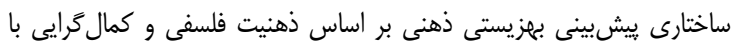

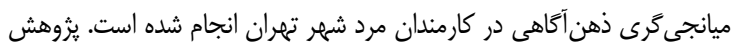

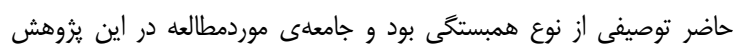

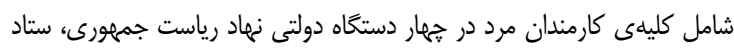

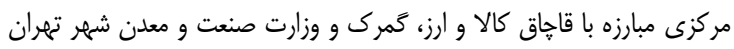

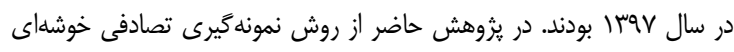

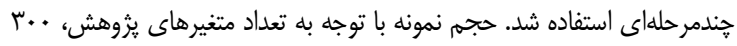

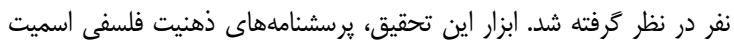

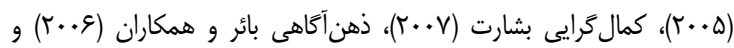

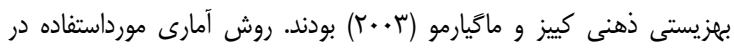

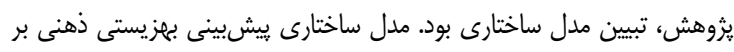

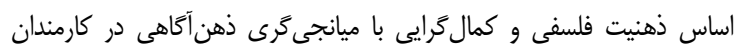

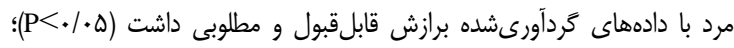

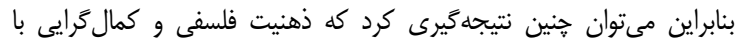

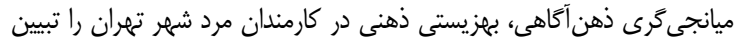
بجزيستى ذهنى، ذهنيت فلسفى، كمال كرابي، ذهن آكاهى، معادلات ساختارى از حدود دهه •عو1، افزايش توجه به رشد روانشناختى و ظهور 
كه باعث ادراك درستى از واقعيت ييرامنى مىشود. مفهوم ذهن

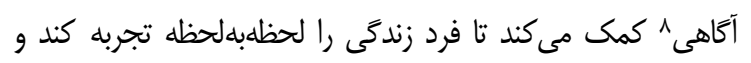

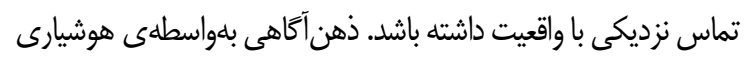

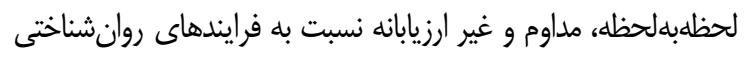

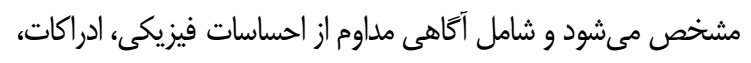

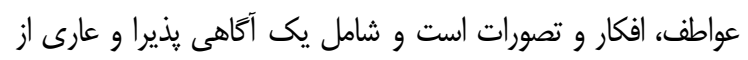

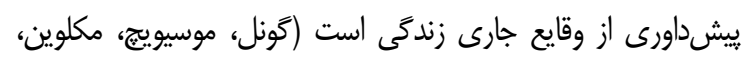

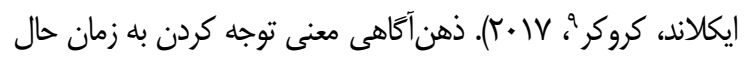

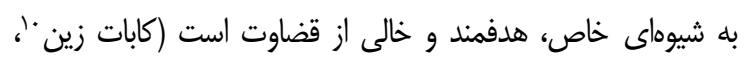

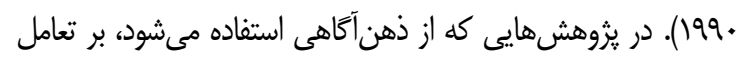

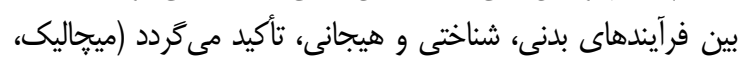

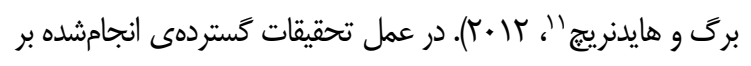

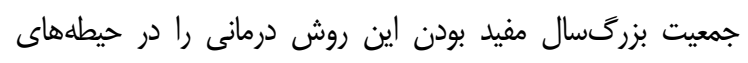

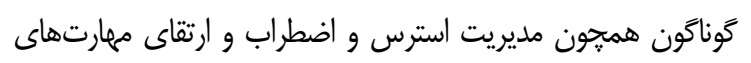

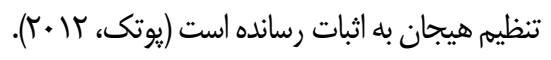

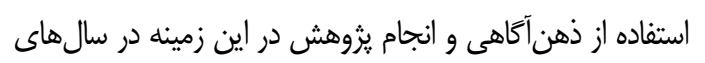

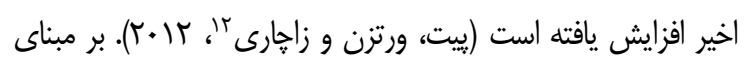

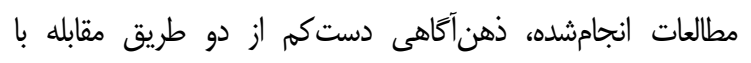

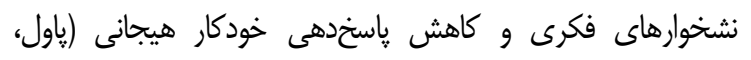

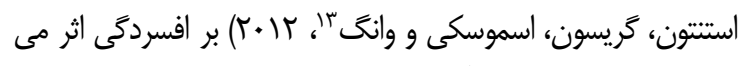

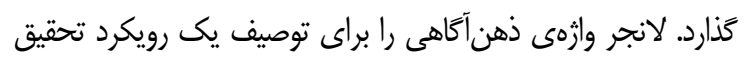

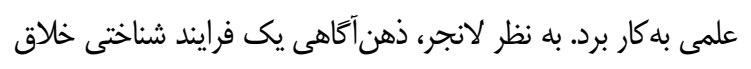

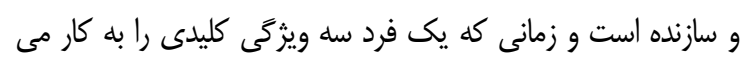

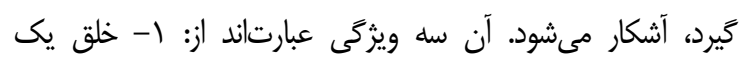

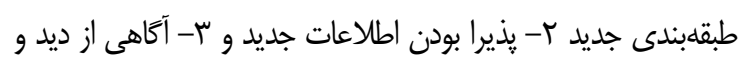

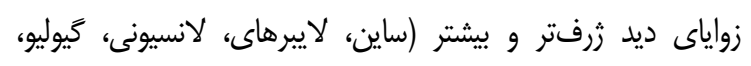

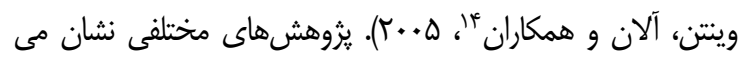

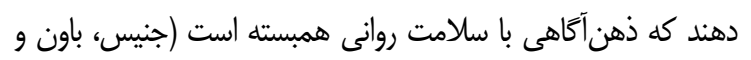

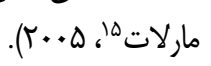

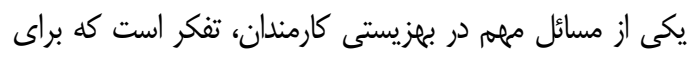

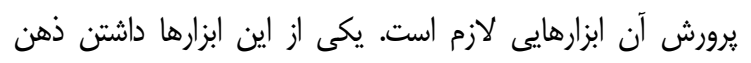

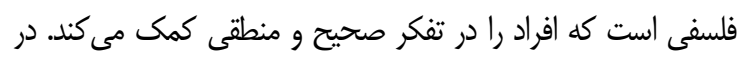

\section{8. mindfulness}

9. Gunnell, Mosewich, McEwen, Eklund, Crocker

10. Kabat Zinn

11. Michalak, Burg \& Heidenreich

12. Piet, Würtzen, \& Zachariae

13. Paul, Stanton, Greeson, Smoski \& Wang

14. Singh, Nirbhay, Lancioni, Giulio, Winton, Alan \& et all

15. Janis, Leigh Bowen, Marlatt,
بهزيستى ذهنى' بهعنوان كاركرد بهينهى انسانها مفهومسازى شد

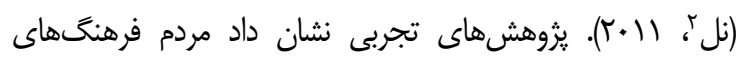

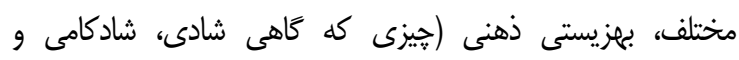

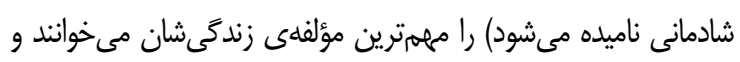

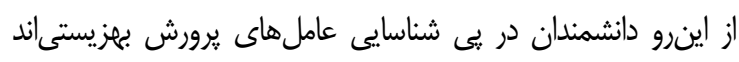

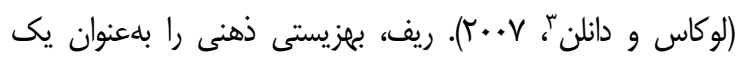

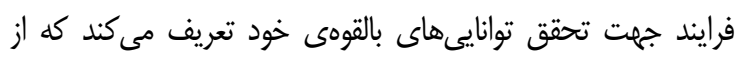

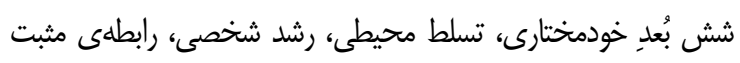

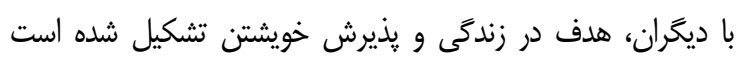

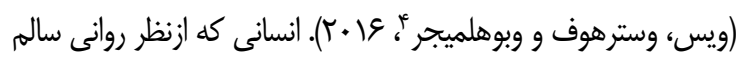

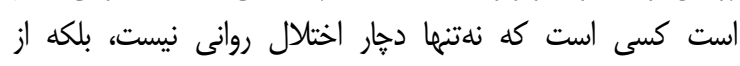

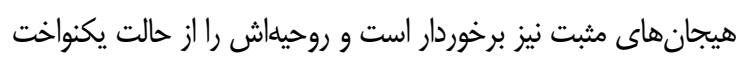

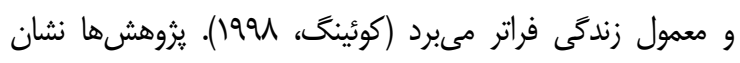

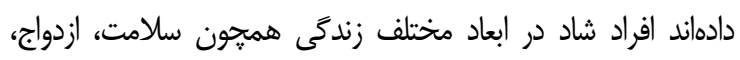

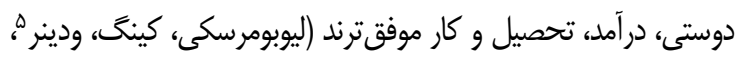

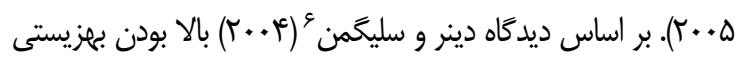

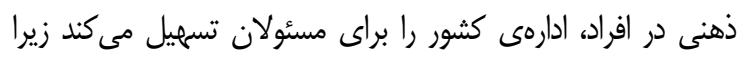

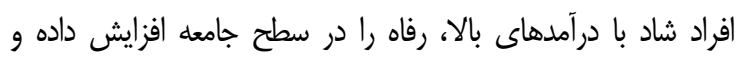

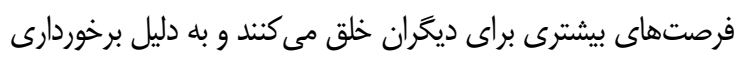

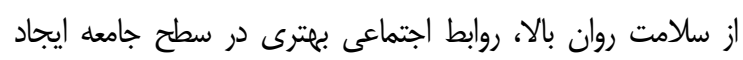

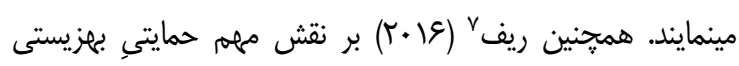

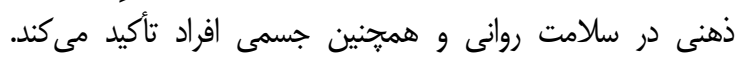

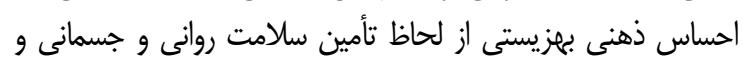

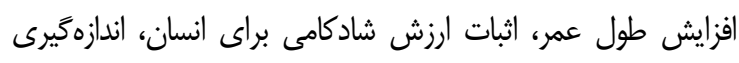

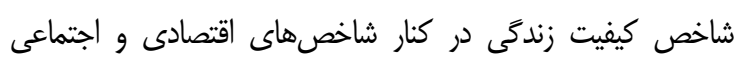

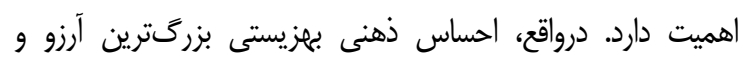

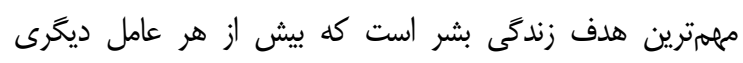

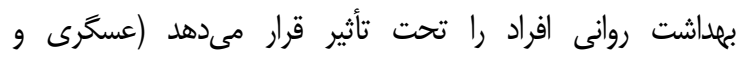

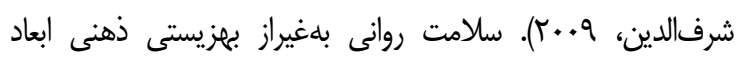

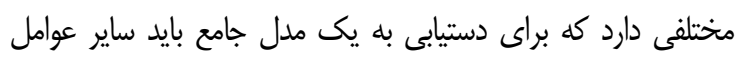
مؤثر رانيز مورد بررسى قرار داد.

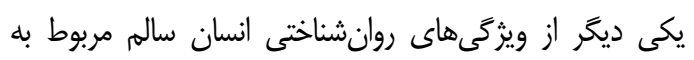

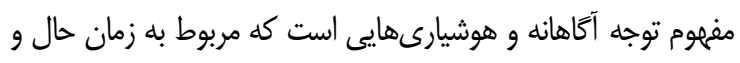

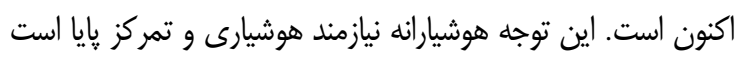
1. Subjective-Wellbeing
2. Nel
3. Lucas, Donnellan
4. Weiss, Westerhof \& Bohlmeijer
5. Lyubomirsky, King, Diener
6. Diener \& Seligman
7. Ryff 
وضع استانداردهاى بسيار بالا براى عملكرد و كرايش به ارزيابى

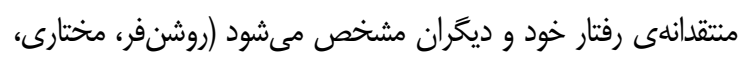

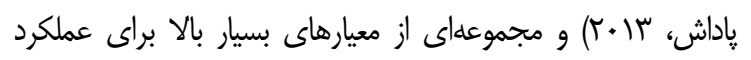

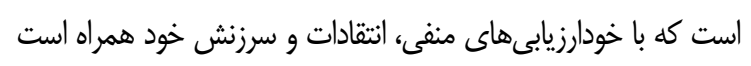

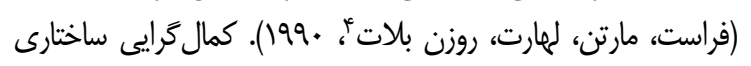

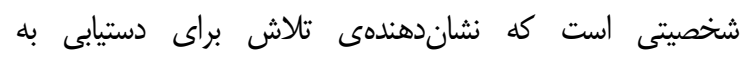

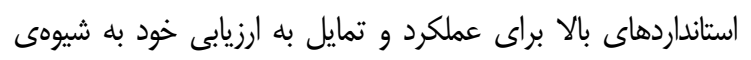

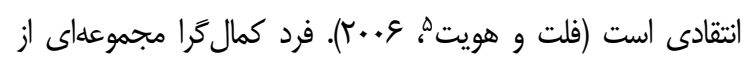

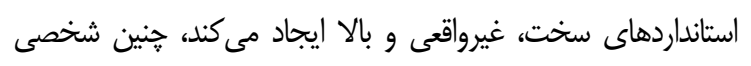

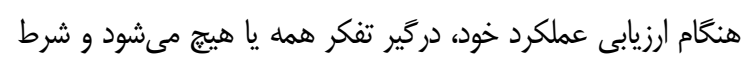

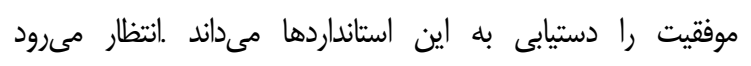

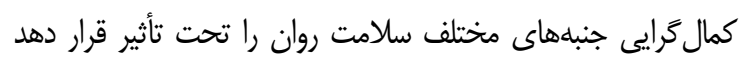

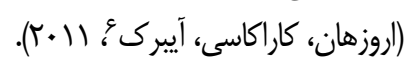

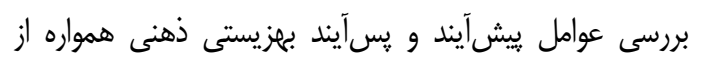

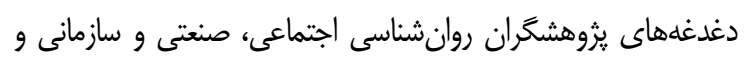

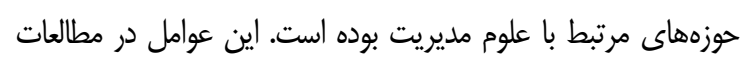

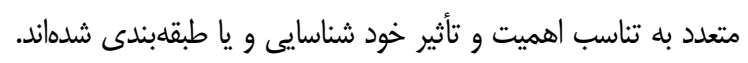

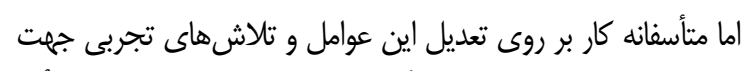

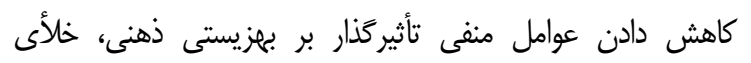

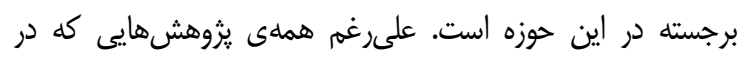

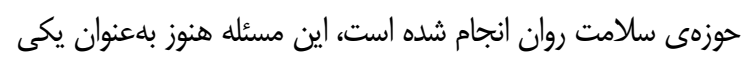

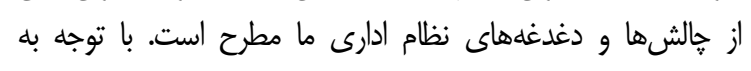

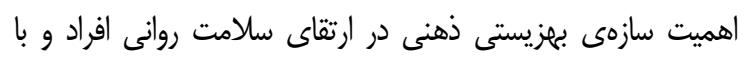

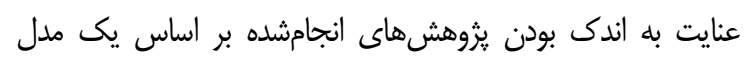

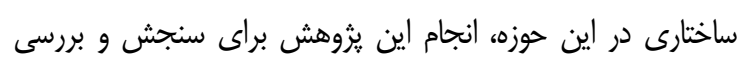

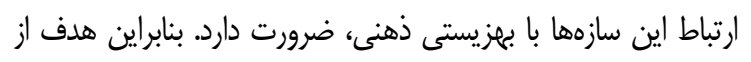

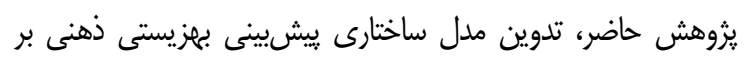

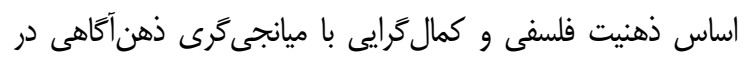

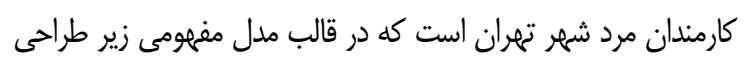

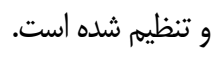

با توجه به يشتوانهى نظرى و يخوهشى موجود، اين بزوهش

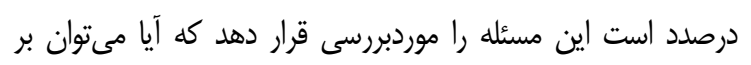

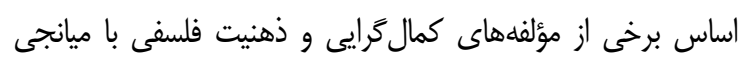

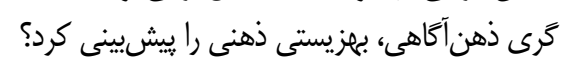

4. Frost, Marten, Lahart \& Rosenblate

5. Flett \& Hewitt

6. Erozhan, Karakasy, Ayberk
خصوص ذهنيت فلسفى' اسميت معتقد است تفكر منطقى اساس كار

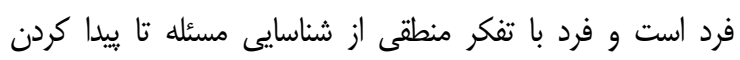

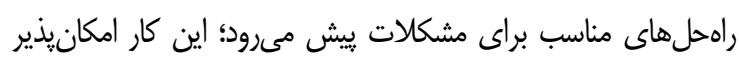

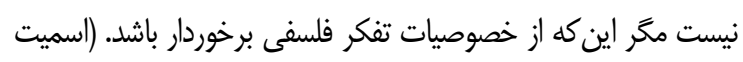

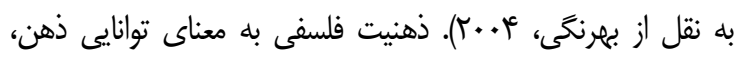

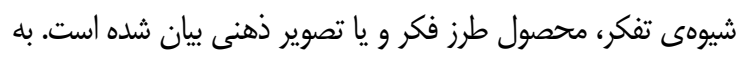

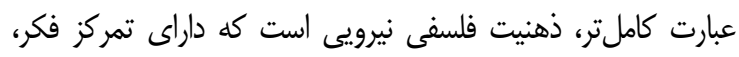

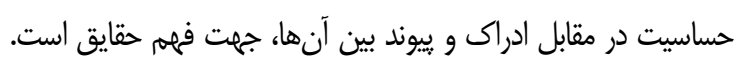

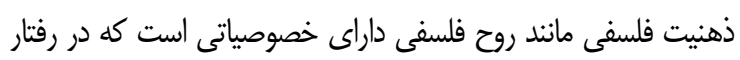

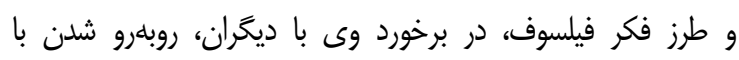

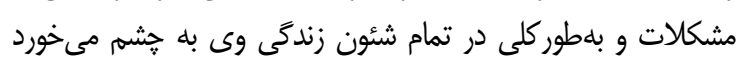

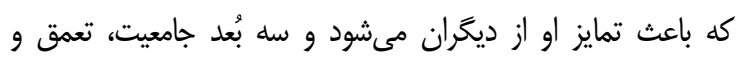

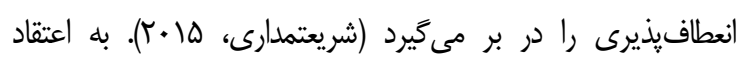

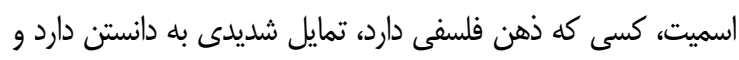

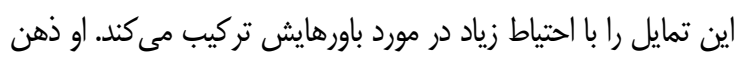

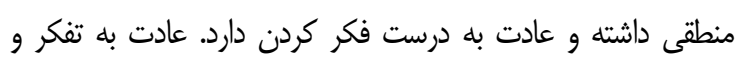

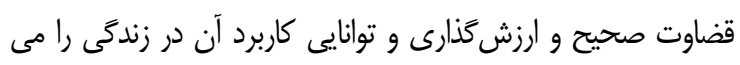

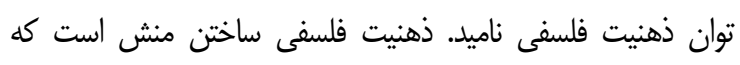

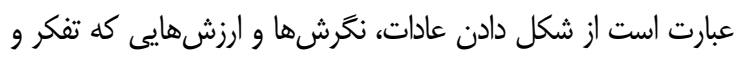

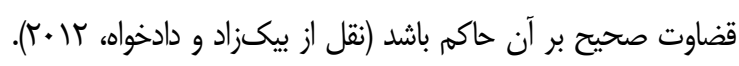

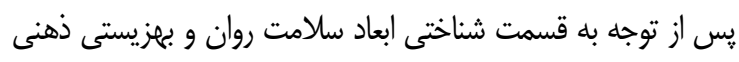

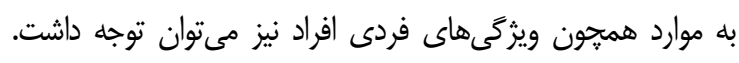

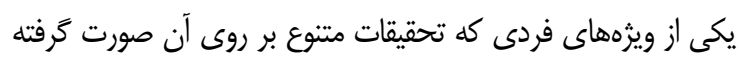
است كمال كرايى باست.

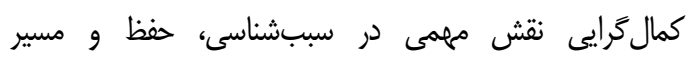

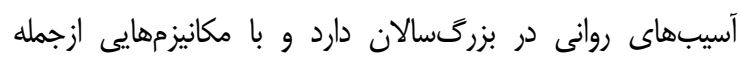

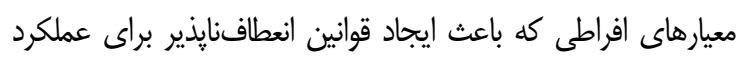

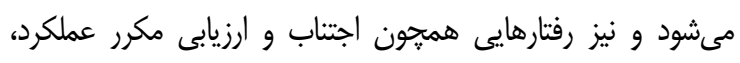

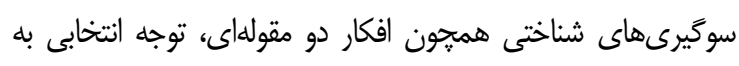

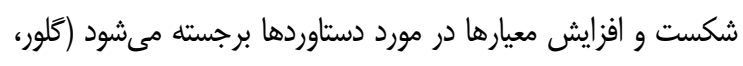

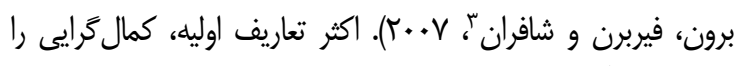

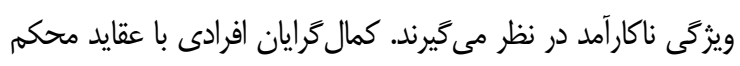

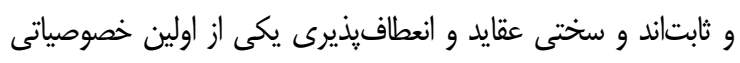

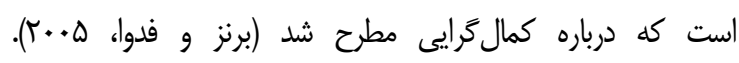

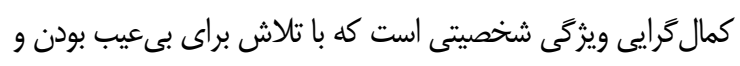

1. Philosophy Mindedness

2. Perfectionism

3. Glover, Brown, Fairburn, Shafran 


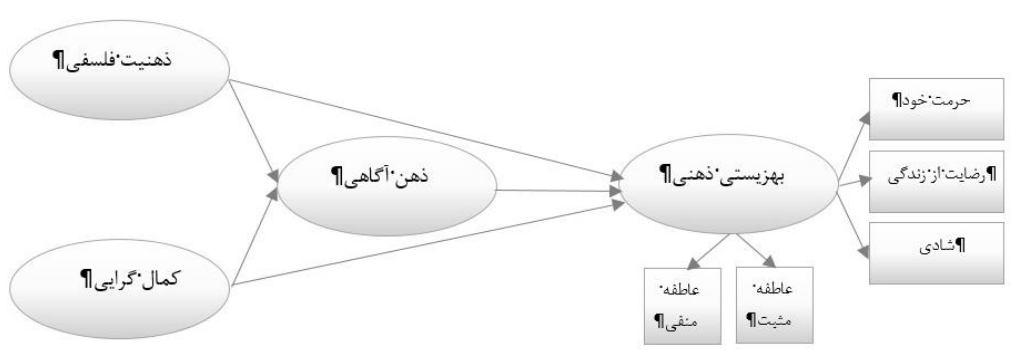

شكل ا. مدل مفهومى تحقيق

مختلف، انتخاب شدند. براى اجراى يُوهش، در ابتدا مجوزهاى لازم

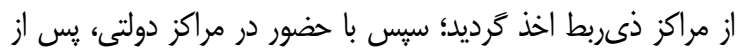

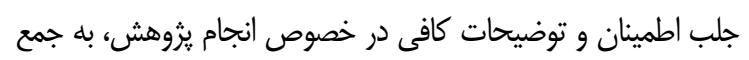

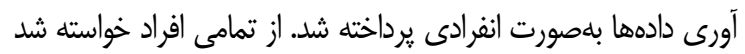

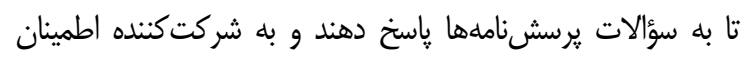

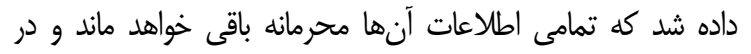

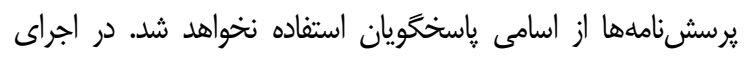
يرسشنامه نيز هيج محدوديت زمانى وجود نداشت و باستخدهندكان إنان

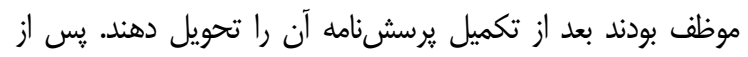

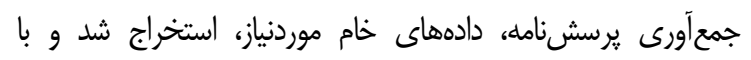
استفاده از نرمافزار آمارى

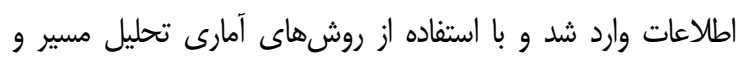
مدليابى ساختارى مورد تجزيهوتحليل قرار ترفت.

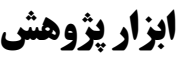

\section{مقياس كمال كرايى جندبُعدى تهران ('TMPS)، (بشارت، Y••†)}

يك مقياس • بّ سؤالى است و سه بُعد كمال كرايى خويشتنمدار،

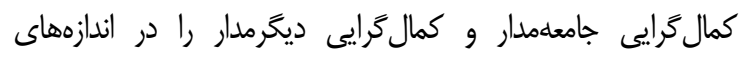

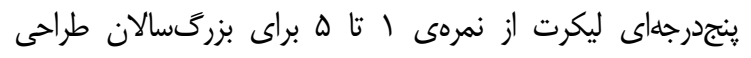

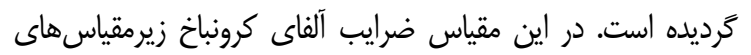

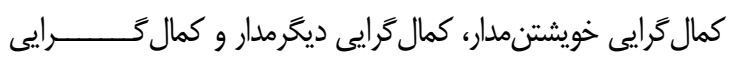

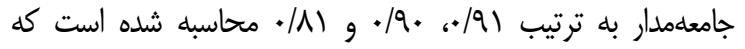

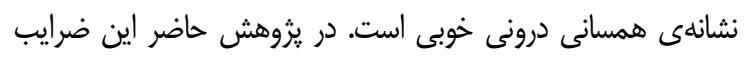

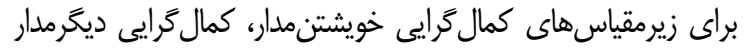
و كمال كرايى جامعلمدار و كمال

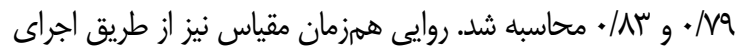
همزمان مقياس مشكلات بين فردى (هروويتز، روزنبرك، بائر، ارنو و و

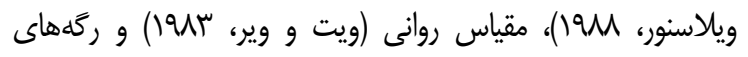

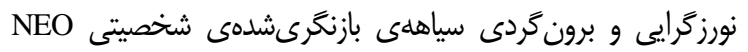

1. Tehran Multidimensional Perfectionism Scale

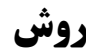

روش اين يزوهش توصيفى - همبستخى و جامعلى مورد مطالعه

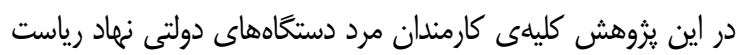

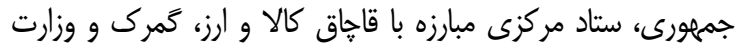

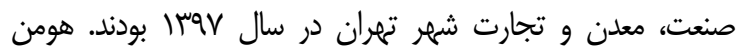

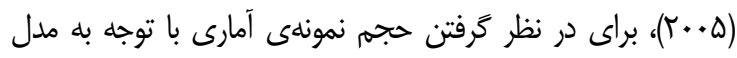

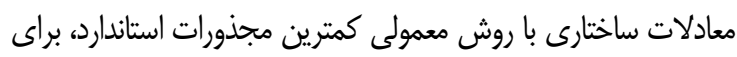

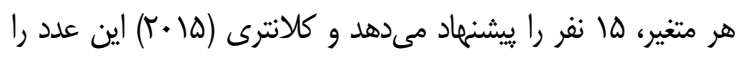

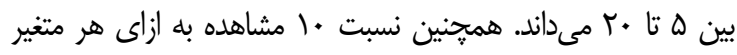

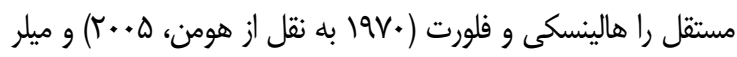

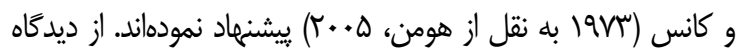

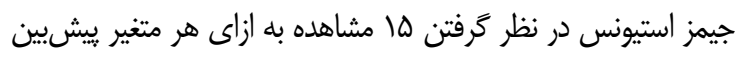

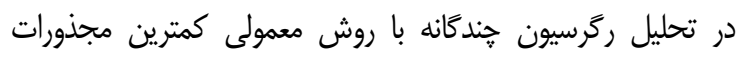

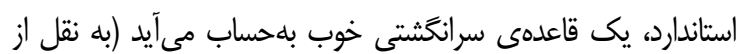

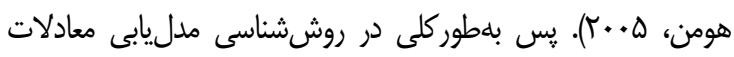

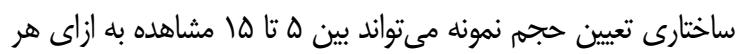

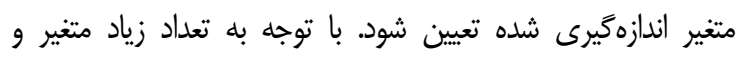

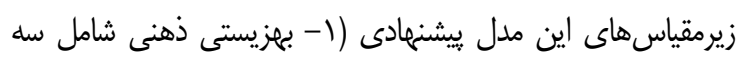

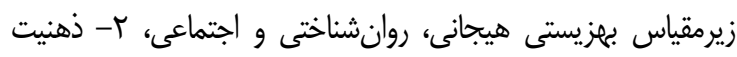

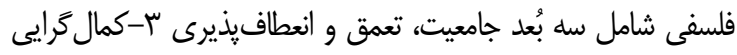

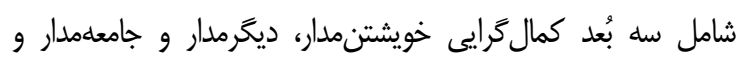

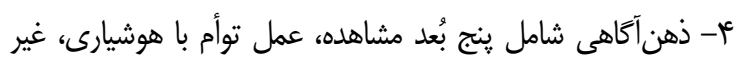

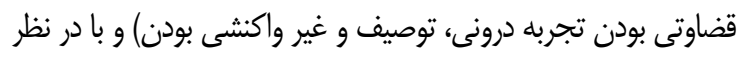

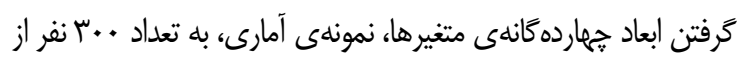

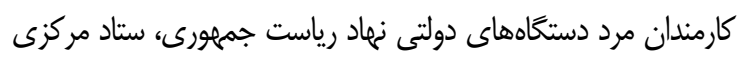

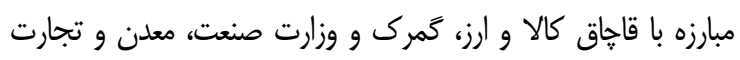

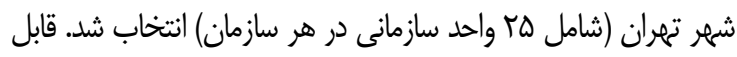

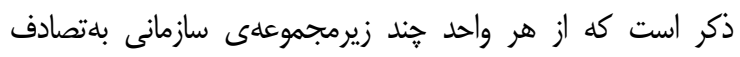

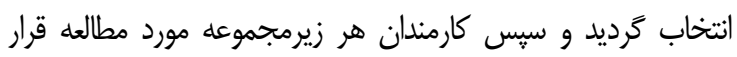

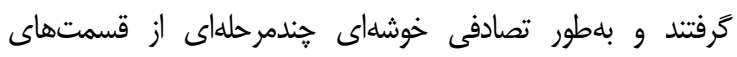


اعتبار مجموع هر دوى اين مقياسها م/• و بالاتر بود (كىيز و

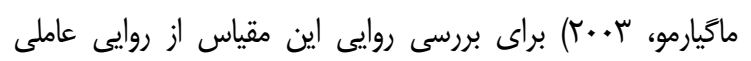

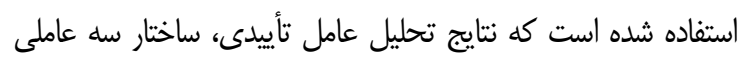

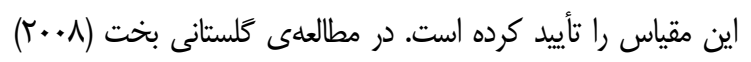

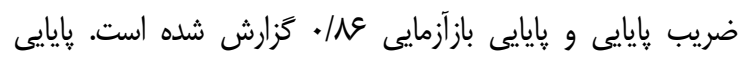

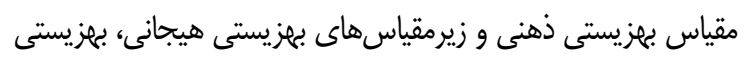

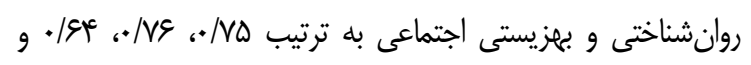

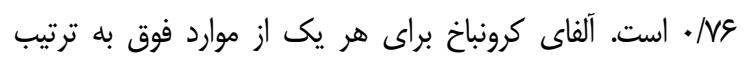

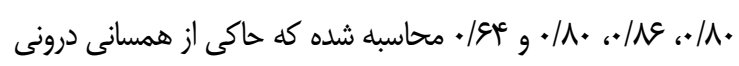

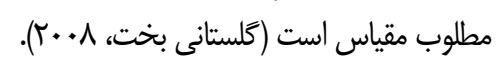

\section{يرسشنامدى ذهنيت فلسفى فيليب ج. اسميت}

ذهنيت فلسفى الكَوى تفكرى است كه داراى سه مؤلفهى

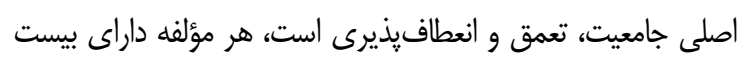

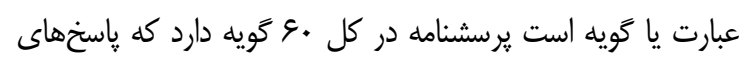

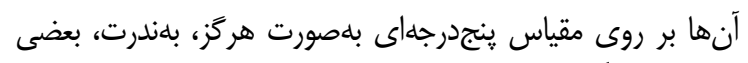

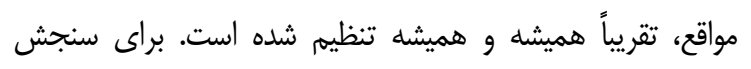

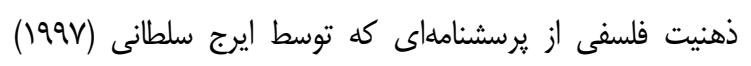

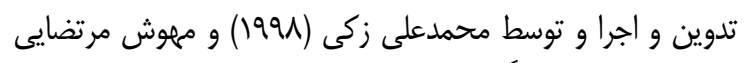

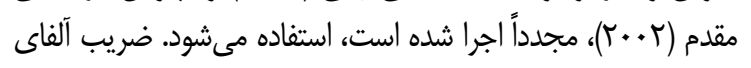

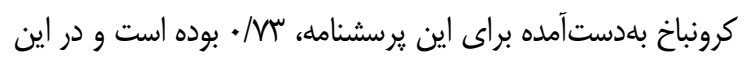

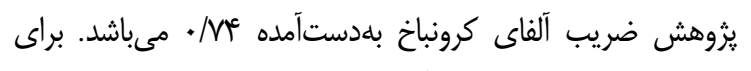

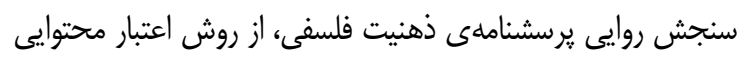

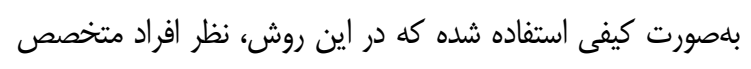

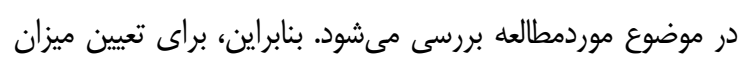

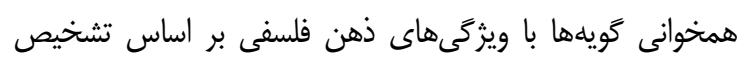

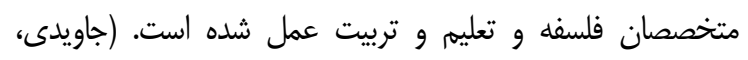

$$
\text { ابوترابى، • • (r) }
$$

\section{يافتهها}

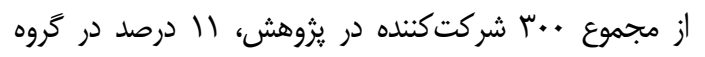

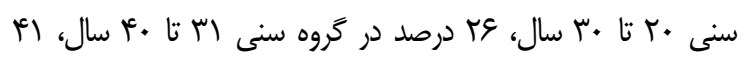

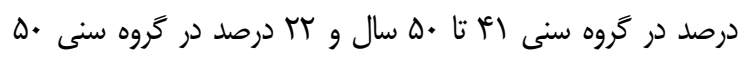

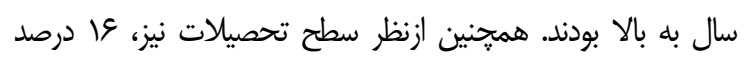

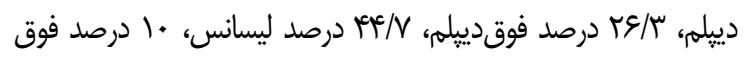

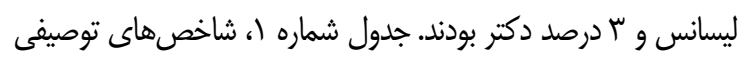
مربوط به متغيرهاى يثوهش را را ارائه مى كند.
(كاستا و مك كريريال، 1997) محاسبه كرديد. نتايج ضرايب

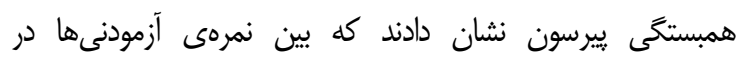

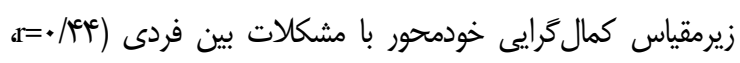
(P</.•l)

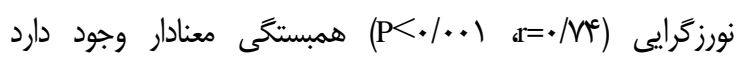

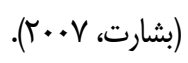

\section{ي برسنامهى ذهن آكاهى}

مقياس خودسنجى حو آيتمى است كه توسط بائر و همكاران

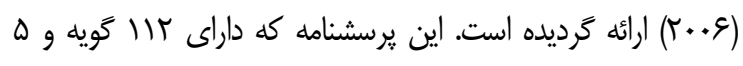

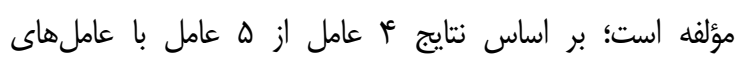

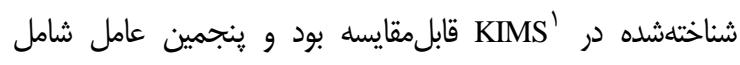

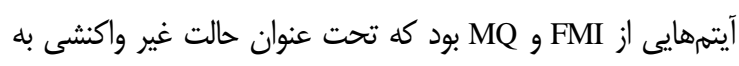

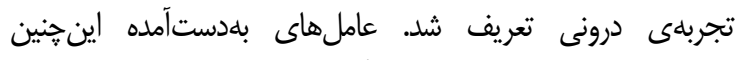

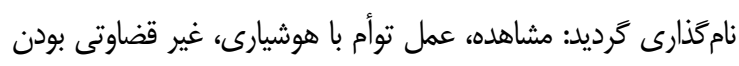

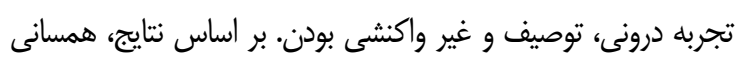

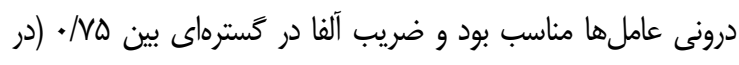
عامل غير واكنشى بودن) تا (9) • (در عامل توصيف) قرار داشت.

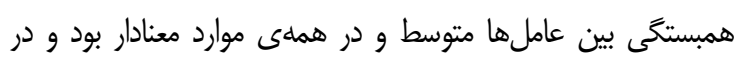

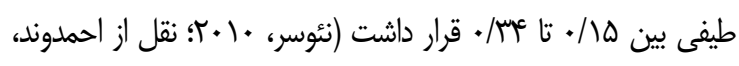

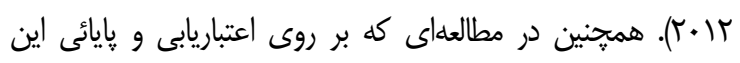

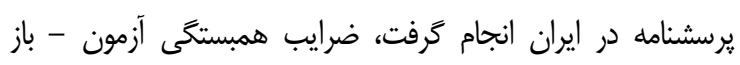

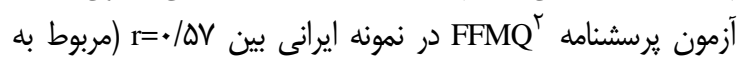

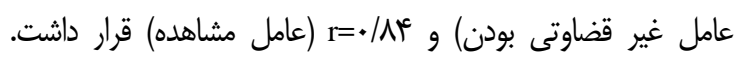

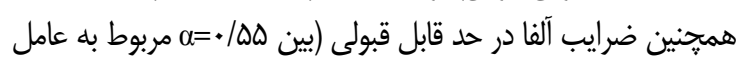

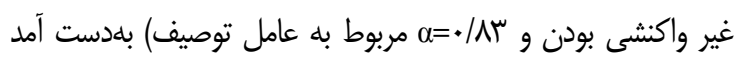

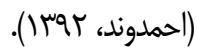

\section{يرسشناملى بهزيستى ذهنى كييز و ماكيارمو}

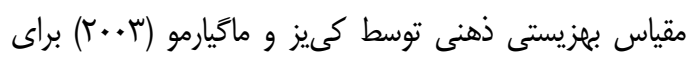

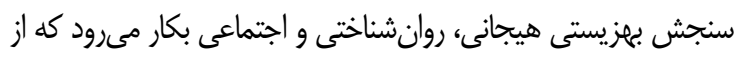

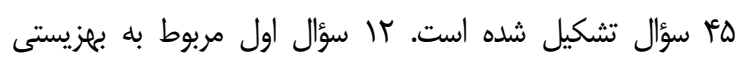

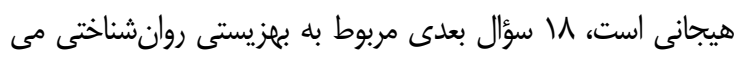

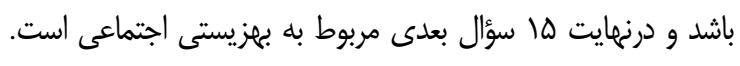

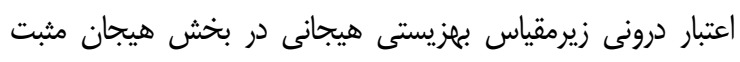

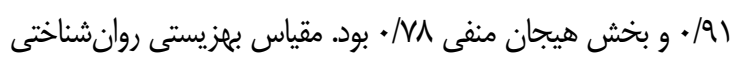

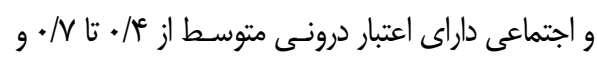

1. Kentucky Inventory of Mindfulness Skills

2. Five Facet Mindfulness Questionnaire (FFMQ) 
جدول ا. آمارههاى توصيفى (مركزى و يراكندگى) متغيرهاى يزوهش (تعداد +." نفر)

\begin{tabular}{|c|c|c|c|c|c|c|c|}
\hline كثيدكى & جولَّى & انحر اف معيار & ميانكَين & بيشترين مقدار & كمترين مقدار & متغير & \\
\hline $1 / \Delta V$ & $-1 / r$ & 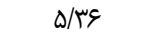 & 1ه/QH & rQ & • & جامعيت ل & \multirow{4}{*}{ 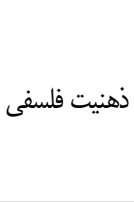 } \\
\hline$-\cdot / I V$ & $-\cdot / \cdot V \Delta$ & $r / 4$. & $\mid r / q \Lambda$ & Me & - & تعمق & \\
\hline$-\cdot /$ KA & $-\cdot / 1 \cdot 1$ & $r / \& \Delta$ & $19 / 19$ & ع & r & انعطافيذيرى & \\
\hline $1 / \cdot 18$ & $-1 / \Delta T Y$ & $1 . / 9 \mathrm{~V}$ & $F \Delta / f$. & $n$ & $\Delta$ & ذهنيت فلسفى (نمرهى كل) & \\
\hline$-1 / 1 n$ &.$- / \mathrm{WW}$ & $9 / \mu r$ & $r M / \Lambda$. & rV & r & جامعلمدار & \multirow{4}{*}{ كمال كرايى } \\
\hline$-\cdot / \Delta M$ & $-. / 9+a$ & ع ع & $\Delta F / A r$ & וr| (1) & IV & ديخرمدار & \\
\hline$\cdot / A W$ & $-\cdot / \Delta V \varepsilon$ & 1.199 & $r q / \Delta T$ & 89 & 18 & خويشتنمدار & \\
\hline$-\cdot / V \cdot r$ & $-. / 1) 8$ & $\varphi \& / 0$. & $\| \varepsilon / 10$ & rme & rV & كمال گرابع (نمرهى كل) & \\
\hline$-\cdot / / \Delta V$ & $-\cdot / \& \Delta \Delta$ & $r / N$ & $|r / \Delta|$ & ra & $\Delta$ & مشاهده & \multirow{6}{*}{ ذ ذهن آكَاهى } \\
\hline.$/ \cdot \pi$ &.$- / \operatorname{seq}$ & $r / W$ & W/9G & ז & 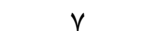 & عمل توأم با هوشيارى & \\
\hline 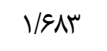 & $-1 / \mu \cdot \Delta$ & $\Delta / \wedge \Delta$ & $\mid V / \& \Lambda$ & ra & \& & غير قضاوتى & \\
\hline •/TAK & $-1 / T \cdot V$ & 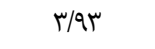 & $1 f / 4$ & ta & v & توصيف & \\
\hline t/FAT & $-1 / \cdot \Delta \Delta$ & $r / M^{c}$ & $10 / v 9$ & ra & $\checkmark$ & غير واكنشى بودن & \\
\hline •/Mr & $-\cdot / v \cdot 9$ & $|\varepsilon| \cdot r$ & $\Lambda \cdot / \cdot r$ & ira & ऍ & ذهنآكَاهى (نمرهى كل) & \\
\hline.$/ 1 \mathrm{~V}$ &.$- / 9 F \Delta$ & V/AT & $19 / 90$ & $\Delta \varepsilon$ & 1 & اجتماعى & \multirow{4}{*}{ بجزيستى ذهنى } \\
\hline - / AAT & $-1 / \cdot 9 V$ & r/N & 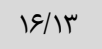 & th & r & 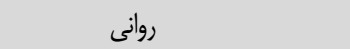 & \\
\hline.$/ 4 W$ & $-. / 1+9$ & $8 / 98$ & $r \cdot / / r$ & f. & 1 & هيجانى & \\
\hline$\cdot / 4 \cdot t^{4}$ & . $/$ M & $10 / 11$ & $\Delta \Delta / \wedge 9$ & $1 \cdot 1$ & $\wedge$ & بجزيستى ذهنى (نمر0ى كل) & \\
\hline \multicolumn{8}{|c|}{ جدول r. بررسى فرض نرمال بودن توزيع متغيرها } \\
\hline \multicolumn{3}{|c|}{ سطح معنادارى (p) } & \multicolumn{2}{|r|}{ مقدار z } & \multicolumn{3}{|c|}{ متغير } \\
\hline \multicolumn{3}{|c|}{$\cdot / \cdot V$} & \multicolumn{2}{|r|}{$1 / 19$} & \multicolumn{3}{|c|}{ ذهنيت فلسفى (نمرهى كل) } \\
\hline \multicolumn{3}{|c|}{$\cdot / \cdot V$} & \multicolumn{2}{|r|}{$1 / r}$. & \multicolumn{3}{|c|}{ كمال گرايع } \\
\hline \multicolumn{3}{|c|}{.$/ 4 V$} & \multicolumn{2}{|r|}{.$/ \Lambda F$} & \multicolumn{3}{|c|}{ ذهن آكاهى (نمر كى كل) } \\
\hline \multicolumn{3}{|c|}{$\cdot / I V$} & \multicolumn{2}{|r|}{$1 / 1$} & \multicolumn{3}{|c|}{ 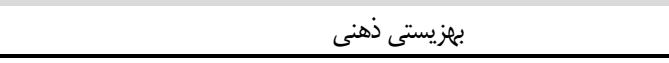 } \\
\hline
\end{tabular}

كمال گرايى، ذهنيت فلسفى و بهزيستى ذهنى بلهنوان متغير ينهان

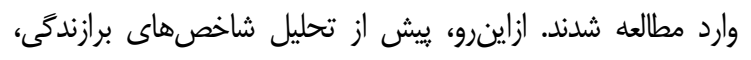

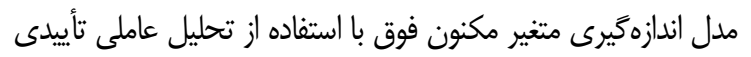
ارزيابى شد. يس از اطمينان از برازش مطلوب مدل اندازهگيرى با دادههاى

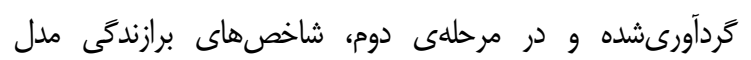

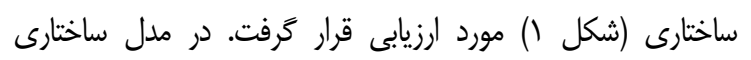

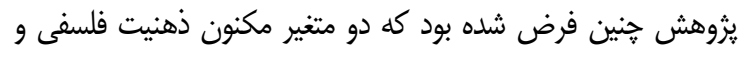

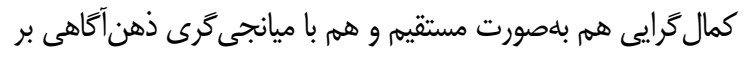
متغير مكنون بهزيستى ذهنى اثر دارد.

جدول شماره س شاخصهاى برازش مدل را با استفاده از نرمافزار AMOS با توجه به مقادير شاخصهاى برازندگى، كه همهى آنها بلنوعى نشاندهندهى برازش مطلوب و قابل قبول مدل با با دادهاى نهاى
همان طور كه جدول شماره r نشان مى نهد، با توجه به مقدار

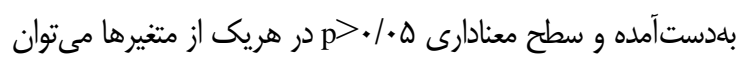

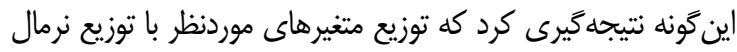

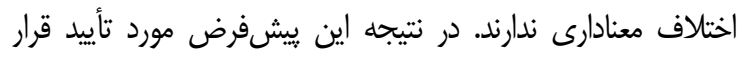

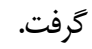
همجنين يِشفرض عدم همخطى متغيرهاى مستقل نيز با

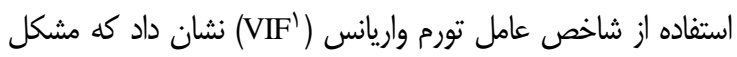

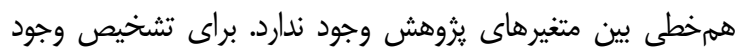

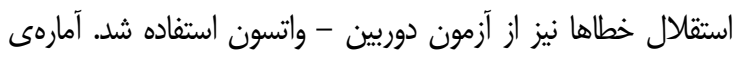

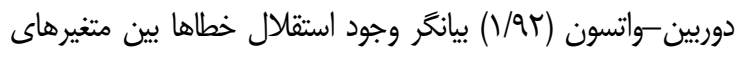
مستقل و وابستهى تحقيق بود. براى تحليل دادهها از مدليابى معادلات ساختارى استفاده شد. در اين يزوهش متغير ذهنآكاهى بلعنوان نشانگ

1. Variance inflation factor 
ذهنى برازندهى دادهاست. نتايج بهدستآمده از مدل ساختارى با توجه به ضرايب تحليل مسير به شكل زير است:
يزوهشى بود و با توجه به نتايج بلددستأمده، فرضياءى اصلى يزوهش

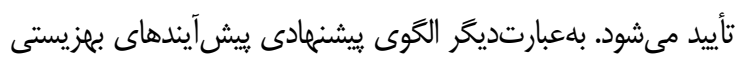

جدول r. شاخصهاى برازش مر مدل

\begin{tabular}{|c|c|c|}
\hline حد مجاز & مقدار & شاخصهاى برازندكى \\
\hline$<\mu$ & $r / M)$ & مجذور كاى \\
\hline$<\cdot / 1$ & .1 .9 & ريشهى خطاى ميانكين مجذورات تقريبى (RMSEA) \\
\hline$>.19$ &.$/ 9$ & شاخص نرمشدمى برازندىى (NFI) \\
\hline$>.19$ &.$/ 9$ & شاخص برازندگى تطييقى (CFI) \\
\hline$>. / 9$ &.$/ 9$. & شاخص برازندگى افزايشى (IFI) \\
\hline$>.19$ &.$/ 91$ & شاخص خوبى برازندكى (GFI) \\
\hline$>.19$ &.$/ 9$. & شاخص خوبى برازندكى تعديلشده (AGFI) \\
\hline
\end{tabular}

شكل r. مدل ساختارى برحسب ضر ايب برآورد شده

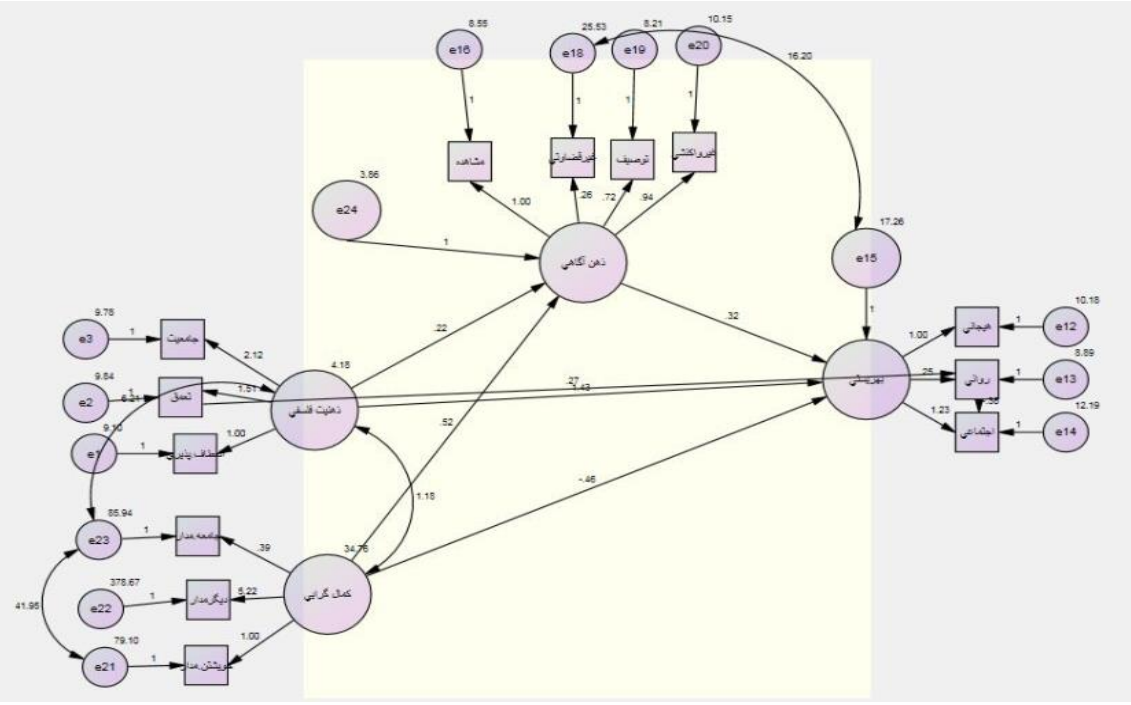

جدول F. نتايج مربوط به برآورد مستقيم مدل

\begin{tabular}{|c|c|c|c|c|c|}
\hline تأييد/رد & سطح معنادارى & C.R. & S.E. & مقدار برآورد ضريب مسير & اثرات مستقيم متغيرها \\
\hline تأييد & $\mathrm{p}<\cdot / \cdot \Delta$ & $1 / 99$ & .11 .9 & $\cdot / / r$ & ذهنيت فلسفى -_-_-- ذهن آكاهى \\
\hline تأييد & $p<\cdot / \cdot \Delta$ & $-V / N$ & .1 .9 & $-\cdot / A r$ & كمال كرايى___-_-_- ذهن آكاهى \\
\hline تأييد & $\mathrm{p}<\cdot / \cdot \Delta$ & $\mathrm{V} / \mathrm{TQ}$ &.$/ 19$ & $\cdot \mid \Delta)^{c}$ & ذهنيت فلسفى _-_-_-_ بهزيستى ذهنى \\
\hline د, & $p>\cdot / \cdot \Delta$ & $1 / r \Delta$ &.$/ \pi \Delta$ & $\cdot \pi r$ & ذهن آكاهى --_-_-- بهزيستى ذهنى \\
\hline تأييد & $p<\cdot / \cdot \Delta$ & $-r / A r$ &.$/ 19$ & $-\cdot / \Delta$ & 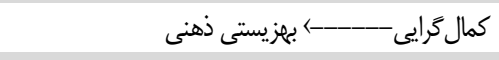 \\
\hline$د$ & $p>\cdot / \cdot \Delta$ & $\cdot / \Lambda F$ &.$/ 94$ &.$/ .48$ & اثر غيرمستقيم ذهنيت فلسفى _-_-_- بـزيستى ذهنى \\
\hline تأييد & $\mathrm{p}<\cdot / \cdot \Delta$ & $-1 / 9$. &.$/ T \Delta$ & $-\cdot / / \lambda r$ & اثر غيرمستقيم كمال كرايى_-_-_- بجزيستى ذهنى \\
\hline
\end{tabular}

رابطهى مستقيم اثر متغير ذهنيت فلسفى بر ذهنآكاهى، مقدار ضريب

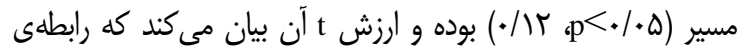

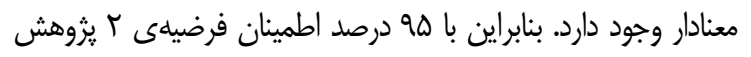

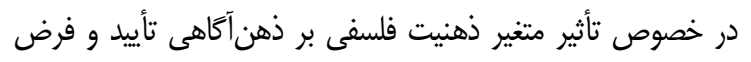

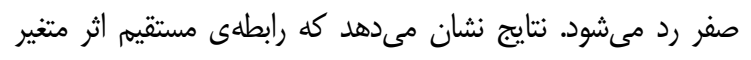

نتايج جدول أ نشان داد كه رابطهى مستقيم اثر متغير كمال

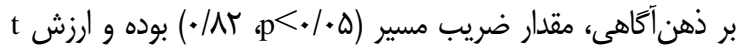

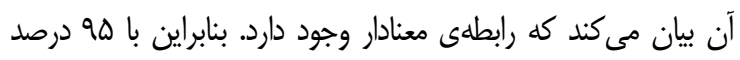

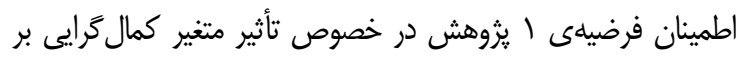

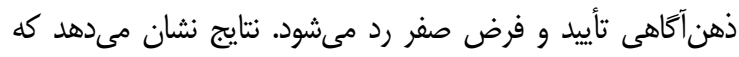


ساختارى فرض شد كه ذهنآكاهى نقش واسطهاى بين ذهنيت

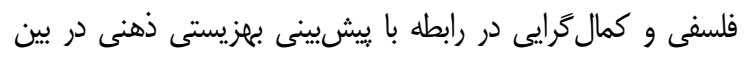

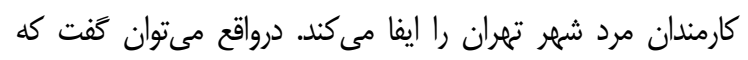

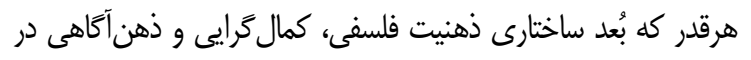

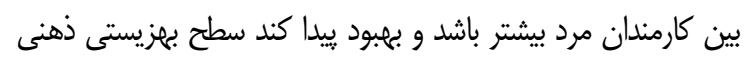

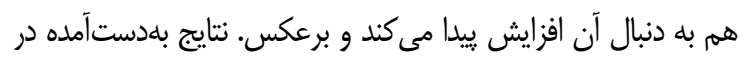

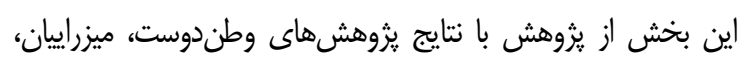

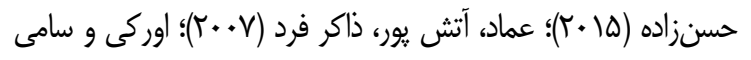
(Y. V)

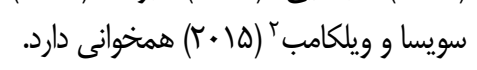

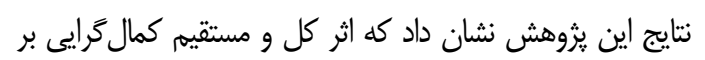

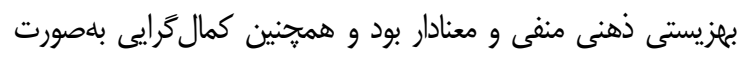

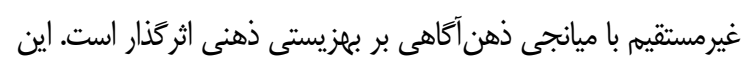

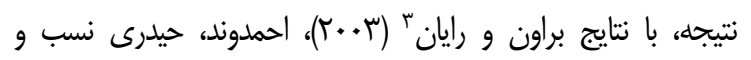

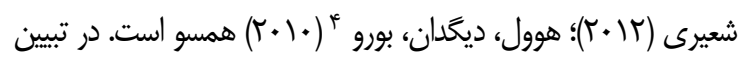

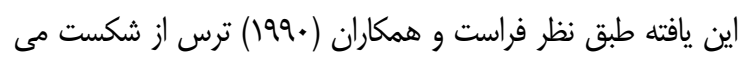

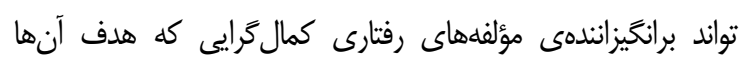

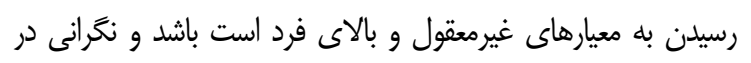

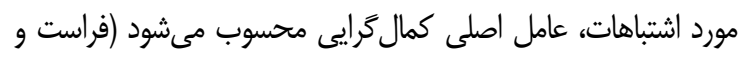

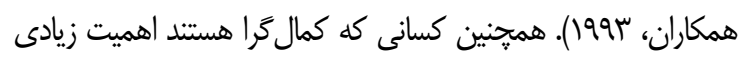

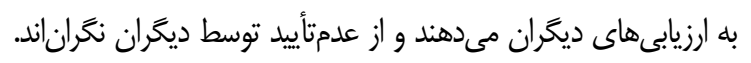

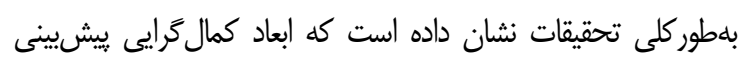

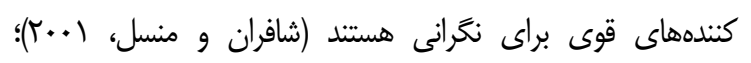
بلطورى كه ممكن است افراد كمال

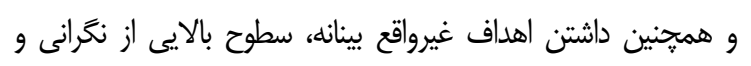

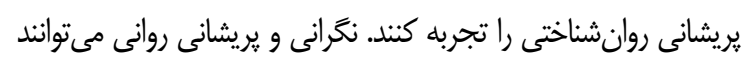

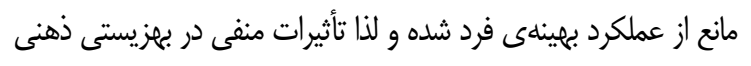

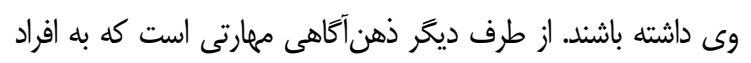

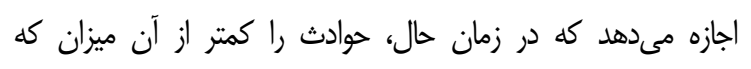

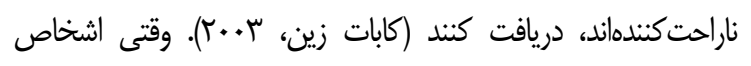

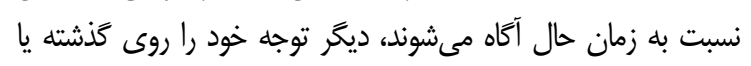

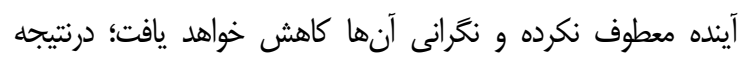

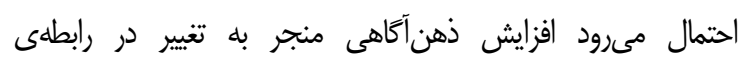

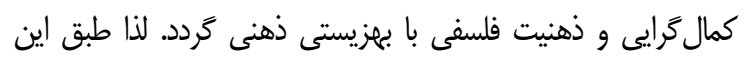

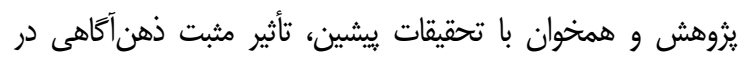

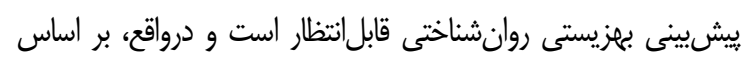

1. Wimberley, Mintz \& Suh

2. Soysa \& Wilcomb

3. Kabat \& Zinn

4. Howell, Digdon, Buro

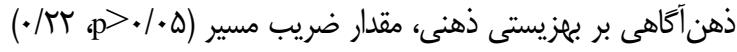

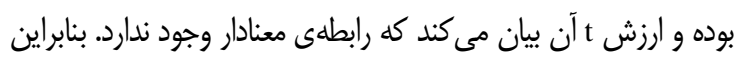

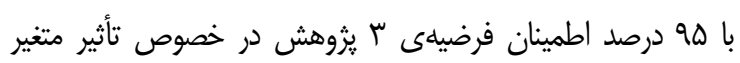

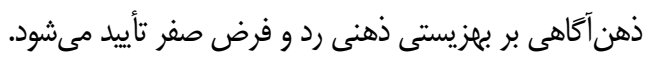

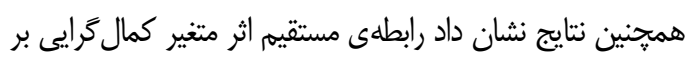

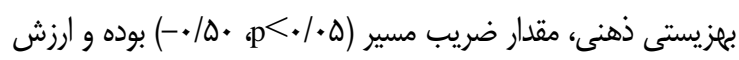

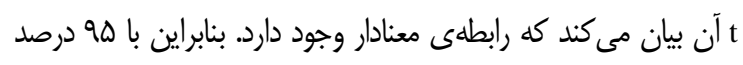

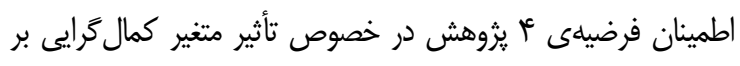

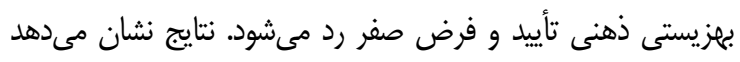

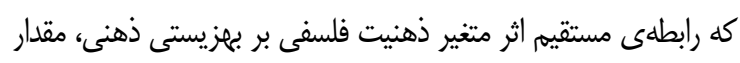

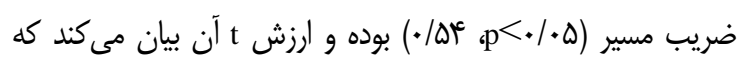

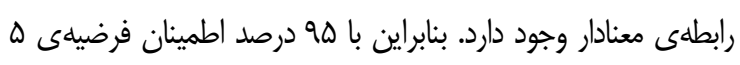

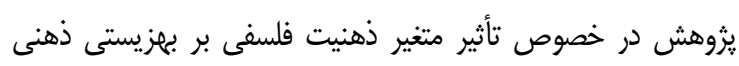

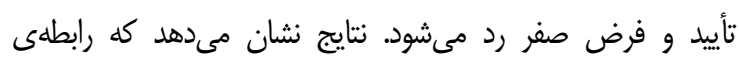

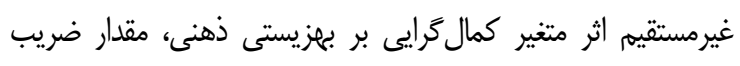

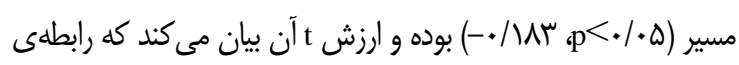

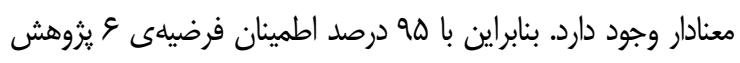

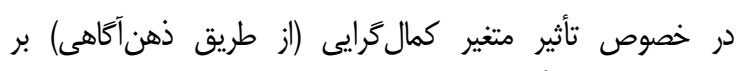

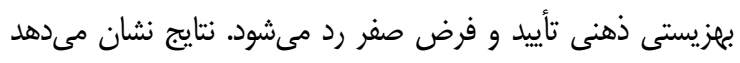

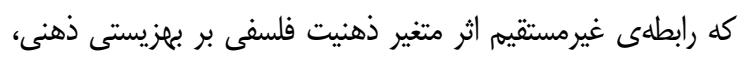

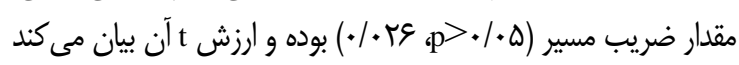

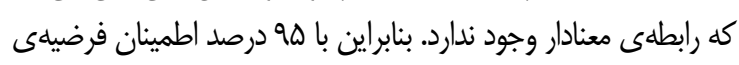

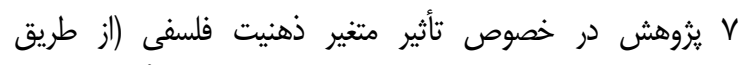

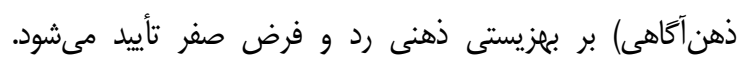

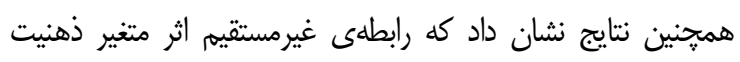

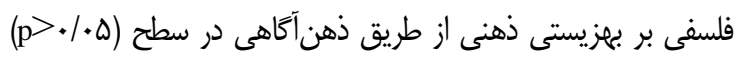

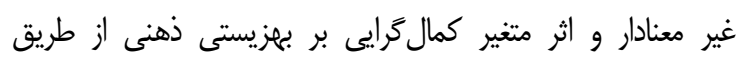

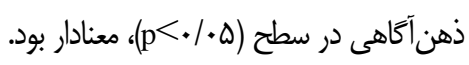

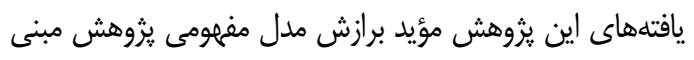

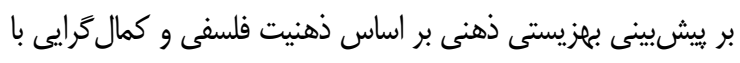

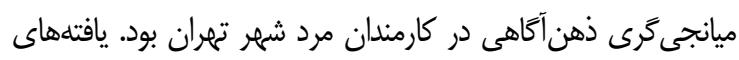

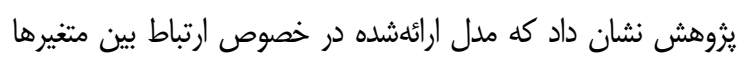
با استفاده از شاخص نهاى نيكوئى برازش، مورد تأييد است.

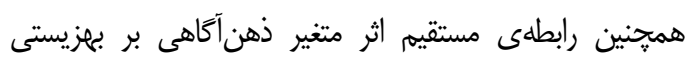

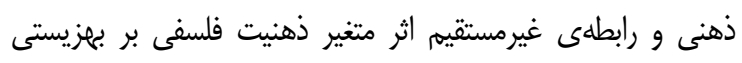

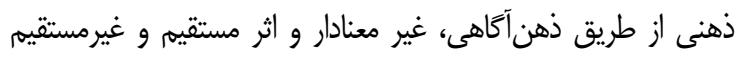

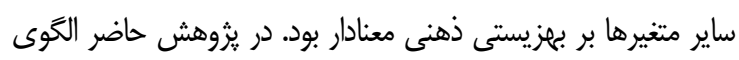


قضاوتها باعث آكاهى بيشتر از خودشان مىشود. بلهوركلى نتايج

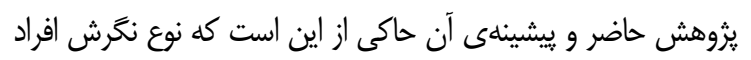

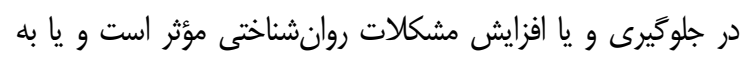

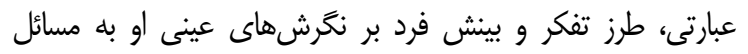
زندگى و نيز رفتار، عواطف و احساسش تأثير كذار هستند.

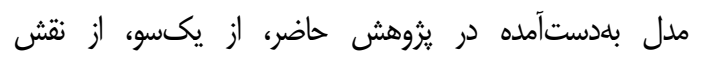

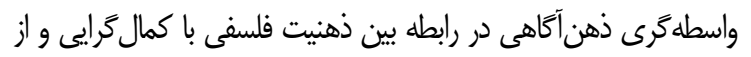

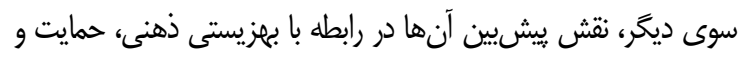

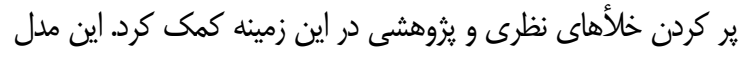

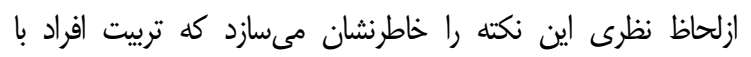

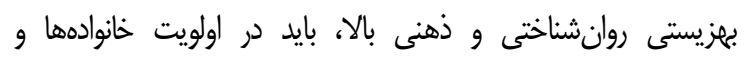

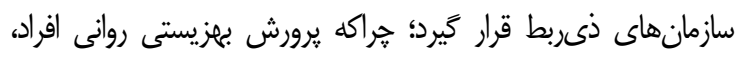

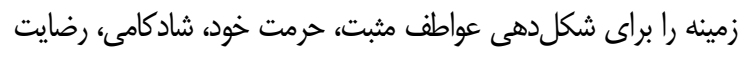

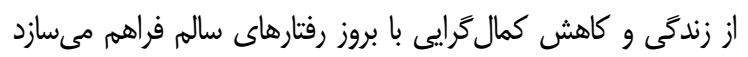

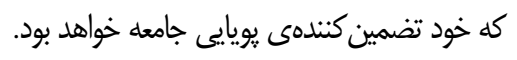
يافتهاى يزوهش حاضر بايد در بافت محدوديتهاى آن تفنسير

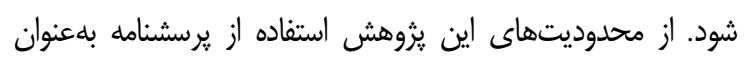

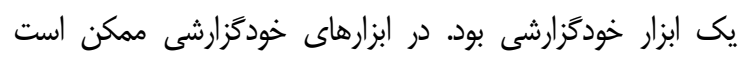

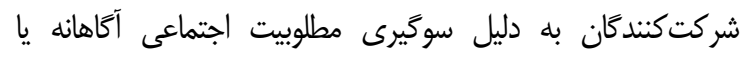

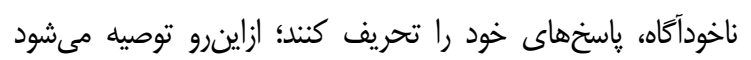

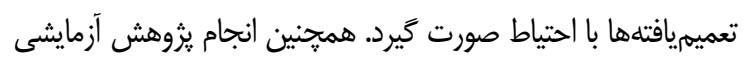

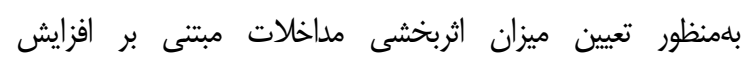

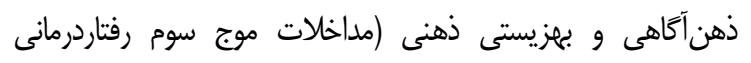

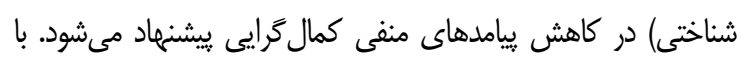

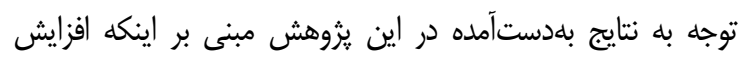

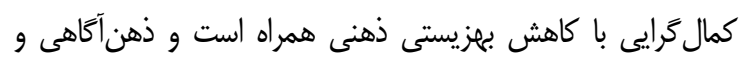

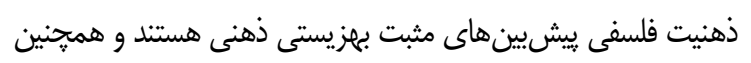

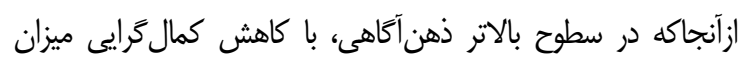

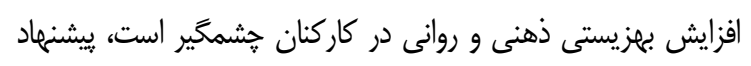

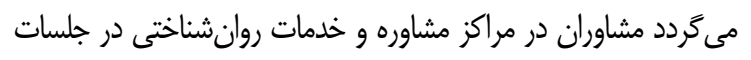

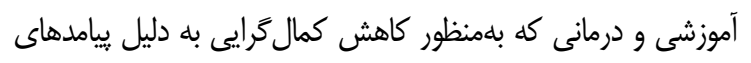

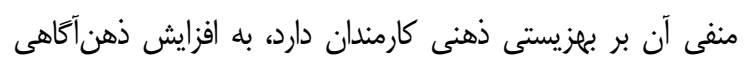
توجه ويزهترى داشته باشند.

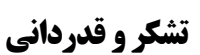

محقق وظيفه خود مىداند از تمامى كاركنانى كه در انجام اين يزوهش، صميمانه همكارى كردند، سياسكزارى نمايد.
يافتهها، با افزايش ذهنآكاهى، بززيستى ذهنى افراد نيز در نمرات

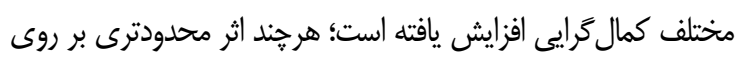

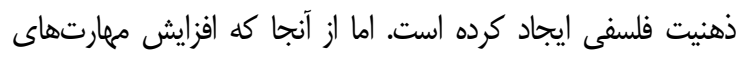

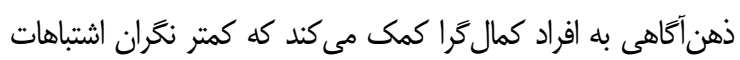

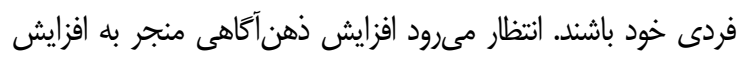

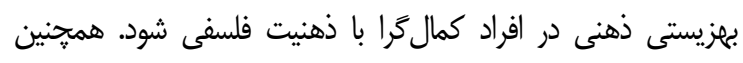

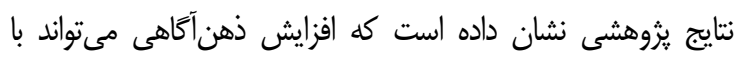

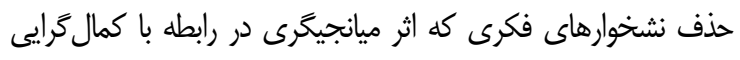

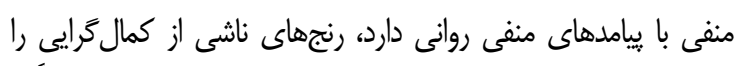

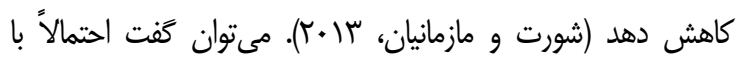

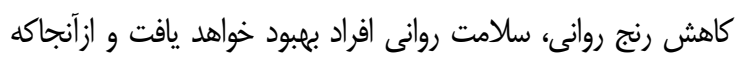

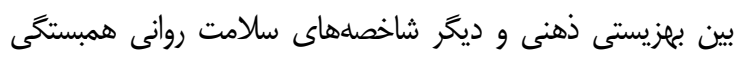

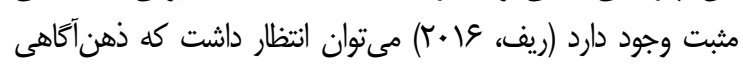

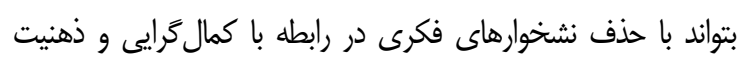
فلسفى با بهزيستى ذهنى نقش ميانجى و تعديل كنندگى داشته باشد.

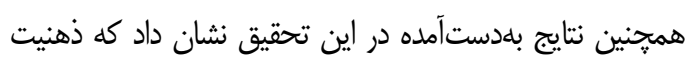

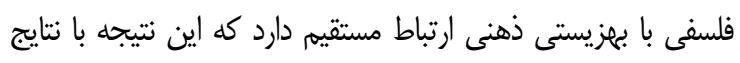

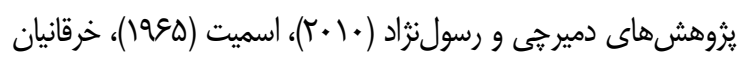

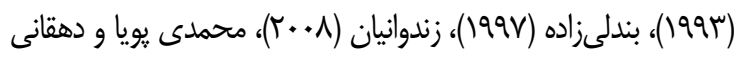

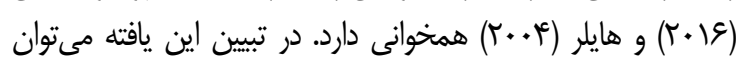

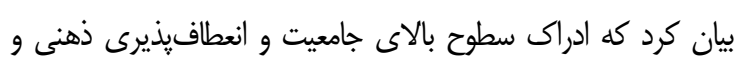

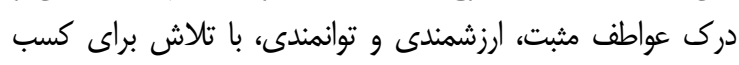

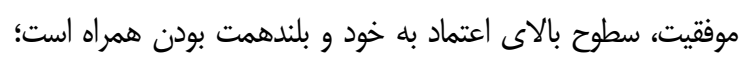

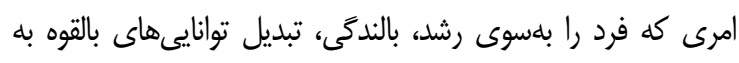

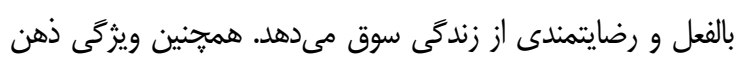

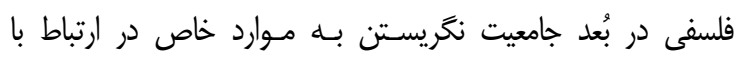

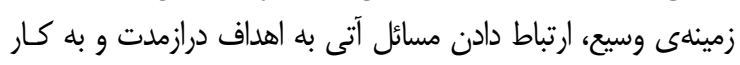

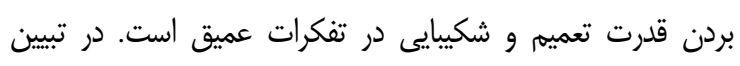

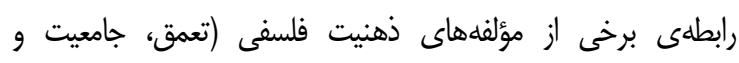

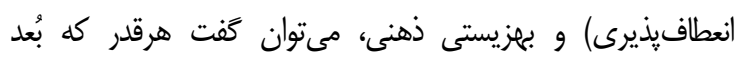

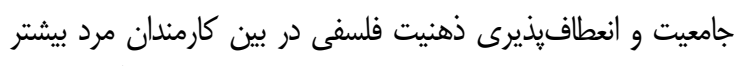

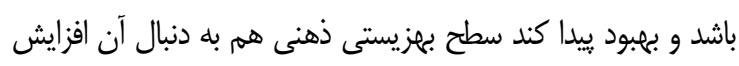

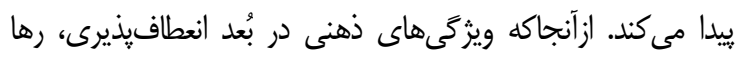

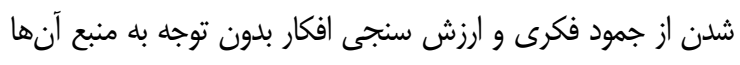

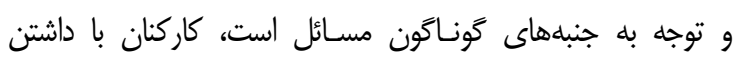

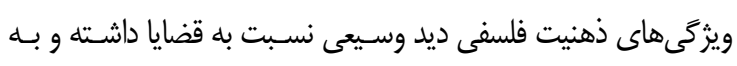

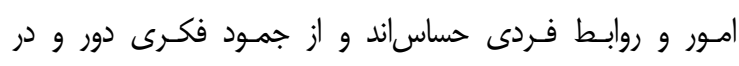

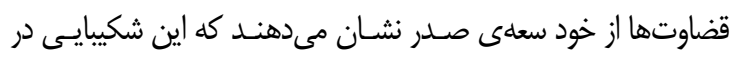




\section{References}

Ahmadvand, Z., heidarinasab, L., shoeiri, M. (2012). Prediction of Psychological Well -Being Based on the Comonents of Mindfulness. Quarterly Journal Of Health Psychology, 1(2), 60-69. [Persian]

Asghari, P. Sharafodin, H. (2009) The Relationship between Social Anxiety, Hope, and Social Support with Students Well-being, Journal of New Findings in Psychology, 3 (9), 25-36. [Persian]

Baer, R. A.; Smith, G. T.; Hopkins, J.; Krietemeyer, J. \& Toney, L. (2006), "Using self-report Assessment methods to Explore Facetsof mindfulness", Assessment. vol 13. no. 1.27-45. [DOI:10.1177/1073191105283504] [PMid:16443717]

Bandelizadeh, N., (1997) The Effect of Philosophical Mind on the Efficiency of School Administrators at Damghan. Master's Degree at Azad University (Tehran-Center). [Persian]

Behrangi, M, R.(2004), Educational administration: the use of theory of management in planning and suppervision. Tehran:Kamal Tarbiat Publishing. [Persian]

Besharat, M. (2007) Construction and validation of Tehran Multidimensional Perfectionism Scale. Psychological Research, Volume 10, Number 1 \& 2, 67-49. [Persian]

Beykzad, j. Dad khah, S. (2012) Philosophical mindset of managers and leadership style. Development Strategy, 32, 100-88. [Persian]

Brown, K. W., \& Ryan, R. M. (2003). The benefits of being present: mindfulness and its role in psychological well being. Journal of Personality and Social Psychology, 84(4), 822. [DOI:10.1037/0022-3514.84.4.822] [PMid:12703651]

Burns, L. R \& Fedewa, B. A (2005), cognitive styles: link with perfectionistic thinking, grand valleg state university, Allendale, MI, 49401, united states, published by Elseirer.

Butt, F. M. (2010). The role of perfectionism in psychological health: Astudy of adolescents in Pakistan. Europe's Journa of Psychology, 6(4), 125 -147. [DOI:10.5964/ejop.v6i4.227]

Costa, P. T., \& McCrae, R. R. (1992). Revised NEO Personality Inventory (NEO-PI-R) and NEO Five Factor Inventory (NEO$\mathrm{FFI}$ ) professional manual. Odessa, FL: Psychological Assessment Resources.

Damerchilli, F., Rasoul Nezhad, A. (2010). Investigating the relationship between philosophical mentality and creativity of faculty members of Islamic Azad universities of Zanjan province. Modern Thoughts in Education Journal, 3(12): 125-144. [Persian]

Diener, E., \& Seligman, M. E. P. (2004). Beyond money: Toward an economy of wellbeing. Psychological Science in the Public Interest, 5, 1-31. [DOI:10.1111/j.0963-7214.2004. 00501001.x] [PMid:26158992]

Emad, S. Atashpour, S. H. Zakerfard, M. A. (2007) Moderating Role of the Mindfulness and Acceptance in Predicting Psychological Well-Being based on Perfectionism in University Students. Journal of Positive Psychology Research. No 7, Volume 3, Issue 02. [Persian]

Erozhan A, Karakasy, Ata s, Ayberk A. (2011). the Relation sheep between perfectionism and Depression in Turkish high school student. J Soc Behav Person; 39(4): 451-64. [DOI:10. 2224/sbp.2011.39.4.451]

Farhadi, A. Rezazadeh Bahadoran, H. Khosravi Bavadi, A. (2018). Constructing and Evaluating the Reliability and Validity of the Philosophical thinking Questionnaire.Journal of Education Strategies in Medical Sciences. No 51, Volume 11, Issue 05. [Persian]

Flett, G. L. \& Hewitt, P. L. (2002). Perfectionism and maladjustment. In G. L, Flett \& P. L., Hewitt (Eds). Perfectionism: theory, research and treatment (PP. 5-33) Washington, DC: American Psychological Association(APA). [DOI:10.1037/10458-000] [PMCid:PMC131054]

Flett, G. L., \& Hewitt, P. L. (2006). Positive versus negative perfectionism in psychopathology: A comment on Slade and Owens's dual process model. Behavior Modification, 30, 472-495. [DOI:10.1177/0145445506288026] [PMid: 16723426]

Frost, R. O., Heimberg, R. G., Holt, C. S., Mattia, J. I., \& Neubauer, A. L. (1993). A comparison of two measures of perfectionism. Personality and Individual Differences, 14(1), 119 -126. [DOI:10.1016/0191-8869(93)90181-2]

Frost, R. O., Marten, P., Lahart, C., \& Rosenblate, R. (1990). The dimensions of perfectionism. Cognitive Therapy and Research, 14(5), 449-468. [DOI:10.1007/BF01172967

Frost, R. O., Marten, P., Lahart, C., \& Rosenblate, R. (2003). The dimensions of perfectionism. CognitiveTherapy and Research, 14, 449-468. [DOI:10.1007/BF01172967]

Glover, D. S., Brown, G. R., Fairburn, C. G., \& Shafran, R. (2007). A preliminary evaluation of cognitive-behavior therapy for clinical perfectionism: A case series. British Journal of Clinical Psychology, 46: 85-94. [DOI:10.1348/014466506X 117388] [PMid:17472203]

Golestanibakht T, Hashemiyan K, Pourshahriyari M, Banijamali $S$. Proposed model of subjective well-being and happiness in the population of Tehran: Alzahra; 2008.

Gunnell KE, Mosewich AD, McEwen CE, Eklund RC, Crocker PRE. (2017). Don't be so hard on yourself! Changes in selfcompassion during the first year of university are associated with changes in well-being. Pers Individ Differ.107:43-8. [DOI:10.1016/j.paid.2016.11.032]

Hiller. Jack H.; Reed G.Williams, Dicter H. Paulus, (2004). Relationships of Philosophic Mindedness and Intellectual Self-Confidence with Verbal Ability and Deductive Reasoning Skills. Journal of Education Resources Information Center, eric.ed.gov.

Hooman, H. A. (2005) Structural equation modeling with Lisrel application. Tehran, The Center for Studying and Compling University Books in Humanitics (SAMT). [Persian]

Horowitz, L. M., Rpsenberg, S. E., Baer, B. A., Ureno, G., \& Villasenor, V. S. (1988). Inventory of interpersonal problems: Psychometric properties and clinical applications. Journal of Counsulting and Clininical Psychology, 56, 885-892. [DOI:10.1037/0022-006X.56.6.885]

Howell, A. J.; Digdon, N.; Buro, K. (2010). "Mindfulness predicts sleep-related selfregulation and well-being", Personality and Individual Differences, 48, 419-424. [DOI:10.1016/ j.paid.2009.11.009] 
Janis, Leigh Bowen, Gisarah and Marlatt, Alan (2005). Spirituality, mindfulness and Substance aduse, Addictive Behaviors, Issue 30, pp. 1335-1344. [DOI:10.1016/j.addbeh. 2005.01.010] [PMid:16022930]

Janowski K., Lucjan P. (2012). Worry and mindfulness: the role in anxiety and depressive symptoms. European Psychiatry (Abstracts of the 20th European Congress of Psychiatry). 27 (Supplement 1), P-133: Pages 1. [DOI:10.1016/S09249338(12)74300-6]

Javidi Kalalte, T. Abootorabi, R (2010) Philosophical Mindset and Leadership Style of Managers in Higher Education System, Educational Studies and Psychology, 11 (1), 234211. [Persian]

Joghtaie, M. (2017) Investigating the Relationship between Philosophical Thinking and Positive Perfectionism with Secondary School Teachers' Job Performance. Islamic Azad University of Shahroud. [Persian]

Kabat -Zinn, J. (2003). Mindfulness -based interventions in context: past, present, and future. Clinical psychology: Science and Practice, 10(2), 144 -156. [DOI:10.1093/ clipsy.bpg016]

Kabat-Zinn, J. (1990). Full catastrophe living: using the wisdom of your body and mind to face stress, pain and illness. New York: Delacorte.

Kalantari, Kh. (2015) Structural Equation modeling in socio economic research (with lisrel and simplis software)Tehrean, Agah publication. [Persian]

Keyes, C. L. M., \& Magyar-Moe, J. L. (2003). The measurement and utility of adult subjective well-being. Positive psychological assessment: A handbook of models and measures. 2003: 411- 25. edited by S. J. Lopez and R. Snyder. Washington, DC: American Psychological Association. [DOI:10.1037/10612-026]

Kharaghanian, M. Behrangi, M. R., (1993). Investigating the Relationship between Philosophical Mentality of Educators in Normal Boys 'Schools in District 5 of Tehran Education with Their Teachers' Morale Years 71-72. Master's Degree at Tehran Teacher Training University. [Persian]

Koenig, H. G. (1998) Handbook of religion and mental health, New York: Academic Press.translate by:Shabani, Avaye noor Publications. [Persian]

Limburg K, Watson HJ, Hagger MS, Egan SJ. (2016). The Relationship Between perfectionism and psychopathology. J Clin Psychol. 28. [DOI:10.1002/jclp.22435] [PMid: 28026869]

Lucas, R. E.; Donnellan, M. B. (2007). "How Stable is Happiness? Using the STARTS Model to Estimate the Stability of Life Satisfaction", in: Journal of Research in Personality, 41: 1091-1098. [DOI:10.1016/j.jrp.2006.11.005] [PMid: 188365 11] [PMCid:PMC2083650]

Lyubomirsky, S.; King, L.; Diener, E. (2005). "The Benefits of Frequent Positive Affect: Does Happiness Lead to Success?", in: Psychological Bulletin, 131 (6): 803-855. [DOI:10.1037/0033-2909.131.6.803] [PMid:16351326]

Michalak J., Burg J., \& Heidenreich T. (2012). Don't Forget Your Body: Mindfulness, Embodiment, and the Treatment of Depression. Mindfulness. 3(3): 190-199. [DOI:10.1007/ s12671-012-0107-4]
Mirkamali, M. (2000) Educational leadership administration. Teran, Yastaroon publication. [Persian]

Mohammadipouya, S., Dehghan, M., (2016). Investigates relations among Philosophic Mindedness, education philosophy and quality of work life in teachers student. Modern Thoughts in Education Journal. 11(4):105-120. [Persian]

Mortezaei moghadam, M.(2002). The Influence of Managers' Philosophical Mind on its Decision Making Process at Ferdowsi University of Mashhad. Ferdowsi University of Mashhad.M.A.Thesis. [Persian]

Nel, L. (2011). The psychofertological experiences of masters degree students in professional psychology programms: An interpretative phenomenological analysis. Thesis in fulfilment of the requirements for the degree. Department of Psychology Faculty of The Humanities: University Of The Free State Bloemfontein. 48 - 84.

Oraki, M., sami, P. (2017). The Effect of Mindfulness Integrated Behavior- Cognitive Therapy on psychological well-being and quality of life among multiple sclerosis patients.. QUARTERLY JOURNAL OF HEALTH PSYCHOLOGY, 5(20), 3447. [Persian]

Orth, U., Robins, R. W., \& Widaman, K. F. (2012). Lifespan development of self-esteem and its effects on important life outcomes. Journal of Personality and Social Psychology, 102, 1271-1288. [DOI:10.1037/a0025558] [PMid:21942279]

Paul N. A., Stanton S. J., Greeson J. M., Smoski M. J \& Wang L. (2012). Psychological and Neural Mechanisms of Trait Mindfulness in Reducing Depression Vulnerability. Soc Cogn Affect Neurosci. [DOI:10.1093/scan/nss070] [PMid:22717383] [PMCid:PMC3541493]

Piet, J., Würtzen, H., \& Zachariae, R. (2012). The Effect of Mindfulness-Based Therapy on Symptoms of Anxiety and Depression in Adult Cancer Patients and Survivors: A Systematic Review and Meta-Analysis. Journal of Consulting and Clinical Psychology. [DOI:10.1037/ a0028329] [PMid:22563637]

Potek, R. (2012). Mindfulness as a school-based prevention program and its effect on adolescent stress, anxiety and emotion regulation Ph.D., NEW YORK UNIVERSITY, 184 pages; 3493866

Roshanfar A, Mokhtari s, Padash z. (2013). Effectiveness of psychotraputic Training Based on life quality on perfectionism in Isfahan Counseling Centers. J Healthy Sys Res;6(8) 86-95. 13.

Ryff, C. D. (2016). Articolo Target. Psychological well -being and health: Past, present and future. Psicologia Della Salute. [DOI:10.3280/PDS2016-001002]

Shafran, R., \& Mansell, W. (2001). Perfectionism and psychopathology: A review of research and treatment. Clinical Psychology Review, 21(6), 879 -906. [DOI: 10.1016/S0272-7358(00)00072-6]

Sharyatmadari, A(2015) Principles and Philosophy, Education. Tehran: Amir Kabir Publications. [Persian]

Short, M. M., \& Mazmanian, D. (2013). Perfectionism and negative repetitive thoughts: Examining a multiple mediator model in relation to mindfulness. Personality and Individual Differences, 55(6), 716 -721. [DOI:10.1016/ 
j.paid.2013.05.026]

Singh, N., Nirbhay, Lancioni, E., Giulio, Winton, S., V., Alan Curtis, W., John, Wahler, G., Robert, Sabaavi, Mohamed, Singh, Judy and Kristen, Ma Aleavey (2005). Mindful Staff increase Learinig reduce aggression in adults With developmental disabilities. Research in developmental Disabilities, 23, 18-28

Smith, P. G. (2005) Philosophic - Mindeness in Educational Adminstration. translate by:Behrangi,Kamal tarbiat Publications. [Persian]

Smith, Philip, G. (1965). What is philosophy education?. U.S.A.: McMillan.

Soltani,I.(1997) Measuring the Managers' Philosophical Mindedness.Tadbir Journal,62:16-19. [Persian]

Soysa, C. K., \& Wilcomb, C. J. (2015). Mindfulness, Selfcompassion, Selfefficacy, and Gender as Predictors of Depression, Anxiety, Stress, and Well - being. Mindfulness, 6 (2), 217 -226. [DOI:10.1007/s12671-013-0247-1]

Vatandoust, L., Mirzaeian, B., \& Hasan Zadeh, R. (2015) Comparision of psychological well -being and positive beliefs about worring among perfectionist and non perfectionist student. Indian Journal of Fundamental and
Applied Life Sciences, 5(1), $2507-2513$.

Veit, C. T., \& Wore, J. E. (1983). The structure of psychological distress and well-being in general population. Journal of Consulting and Clinical Psycholog, 51, 730-742. [DOI:10. 1037/0022-006X.51.5.730]

Weiss, L. A., Westerhof, G. J., \& Bohlmeijer, E. T. (2016). Can We Increase Psychological Well -Being? The Effects of Interventions on Psychological Well -Being: A Meta Analysis of Randomized Controlled Trials. Plos One, 11(6), e0158092. [DOI:10.1371/journal.pone.0158092] [PMid: 27328124] [PMCid:PMC4915721]

Wimberley, T. E., Mintz, L. B., \& Suh, H. (2015). Perfectionism and Mindfulness: Effectiveness of a Bibliotherapy Intervention. Mindfulness, 7. 1 -12. [DOI:10.1007/s12671015-0460-1]

Zaki, M. (1998). Investigating the Social Dimensions of Managers' Philosophical Mindset, Management Knowledge. Journal of Management Knowledge. No 41, Volume 11. [Persian]

Zandanian, A., Safayi Moghadam, M., Pak Seresht, J., Sepasi, H., (2008). Identifying and Analyzing the Educational Philosophy of Adult Education Instructors in Yazd Province. Educational sciences J. Chamran University. 5(3): 3-26. [Persian] 